Review

\title{
Challenges in Improving Energy Efficiency in a University Campus Through the Application of Persuasive Technology and Smart Sensors
}

\author{
Anthony Emeakaroha*, Chee Siang Ang and Yong Yan \\ School of Engineering and Digital Art, University of Kent, Kent CT2 7NT, UK; \\ E-Mails: c.s.Ang@Kent.ac.uk (C.S.A.); y.yan@Kent.ac.uk (Y.Y.) \\ * Author to whom correspondence should be addressed; E-Mail: ae226@Kent.ac.uk; \\ Tel.: +44-122-782-3458; Fax: +44-122-745-6084.
}

Received: 4 September 2012; in revised form: 8 November 2012 / Accepted: 9 November 2012 / Published: 19 December 2012

\begin{abstract}
The impact of energy consumption and carbon emission in the UK poses a grave challenge. This challenge is particularly high amongst residents of university campuses, where usage of electricity and carbon emission remain invisible to the students. In student residential accommodation, personal choices and social influences affect electricity consumption and ultimately the resultant reduction in carbon emissions. Therefore, innovative solutions are required to change students' energy consumption behavior, and one promising part of the solution is to present real-time electricity consumption data to students in real-time via a dedicated web platform, while, at the same time, appointing an energy delegate in each hall to induce motivation among the students. The results of some interventions show that immediate energy feedback from smart meters or display devices can provide savings of 5\%-15\%. However, the situation is different; with the complexity in behavior of our target groups "the students who are living in the halls of residence", there are economical and environmental aspects to be addressed in these issues, in the campus halls of residence. Therefore, we propose a system to address this issue, by applying smart sensors (real-time electricity data capture), integration of dedicated visual web interface (real-time electricity feedback display) and an appointed energy delegate in each hall (a motivator). It is expected that this will motivate students living in the halls of residence to reduce their electricity wastage and, therefore, control the energy cost and also reduce the carbon emissions released into the environment. In the present research, we focus on the University of Kent, Canterbury campus to study energy conservation and
\end{abstract}


carbon emission reduction strategies.

Keywords: carbon emission; energy conservation; smart sensors; feedback systems; persuasive interface; environment; behavior change and system architecture

\section{Introduction}

The consumption of electricity in residential buildings is highly dependent on the behavior of the residents. A major challenge for people, who are willing to conserve energy and reduce carbon emissions in their residential units, is the lack of intuitive and persuasive information/feedback about their energy consumption [1]. Neither can they easily identify how much electricity they end up consuming in their households, nor are they able to compare their household consumption to a typical household of similar type, size, and location [1].

However, as studies have shown, a monthly feedback provided on the energy bill is not sufficient [2]. EDF Energy, one of the largest energy vendors in the UK, believes that the challenges of climate change, energy affordability and energy security require the complete transformation of the energy industry by encouraging conservation and carbon emission reduction $[3,4]$.

This is especially important for university campuses, where budgets for campaigns on environmental awareness are constantly falling short, due to a recent increase in electricity prices in the UK by $8.7 \%$ [5]. The current climate change situation demands immediate and pragmatic approaches for systemic shifts in our culture and behavior [3]. In the past, education has played a role in bringing awareness regarding energy conservation and environmental issues, but has not necessarily resulted in sustained behavioral changes, for example, among students across university campuses. In the present study, we aim to address energy issues in university campuses, focusing on students living in the halls of residence. We believe that smart sensors play a vital role in designing a persuasive system that will help students' behavior change. According to Fogg [6], the persuasive technology is broadly defined as a technology that is designed to change attitudes or the behavior of the users through persuasion and social influence.

The initial survey carried out in the students' halls of residence as summarized in Figure 1 and Figure 2, indicates that students have the ability to conserve energy and reduce carbon emission but lack motivation; based on these findings, we proposed our system web interface called "Rapid Green Energy Initiative" (RGei). In this paper, we present the summary of the methodology of the planned pilot intervention, on the students' energy consumption behavior. The result of this intervention will be tested against our proposed student behavior model as detailed in Figure 3. We also outline a design of the proposed system architecture, combining the initiative of a real-time data feedback system, smart sensor, dedicated web interface and an appointed energy delegate, to form a persuasive interface that will induce behavior change among students.

However, we reviewed some related previous work in these areas, specifically applications of smart sensors to obtain a real-time electricity feedback on campus residents. We reviewed the work of Petersen J.E. et al. where they carried out a pilot study in a student dormitory, using real-time visual feedback and incentives. We also reviewed the work of Brewer R.S. et al. 2011, who carried out a 
dorm energy competition focused on sustainable behavior change and energy literacy. We also reviewed the work of Odom W. et al. 2008, who used social incentive and eco-visualization displays toward persuading greater change in dormitory communities. We reviewed the work of Bekker M.J. et al. 2010, in which they carried out experiments to investigate the combined use of visual prompts, daily feedback and rewards to reduce electricity consumption in a university residential hall [7-10]. In each of the above closely related studies we reviewed, the researchers had applied real-time feedback systems to some extent. We also observed that all their studies were based on incentive, competition or rewards. This literally affected the sustainability of the above studies. Therefore, as the target groups were students, their studies suffered from "fall back" and Hawthorns effects. However, the results these studies threw up were archived during their various experiments and they will be discussed in detail later in this paper.

Figure 1. Student energy conservation motivation.

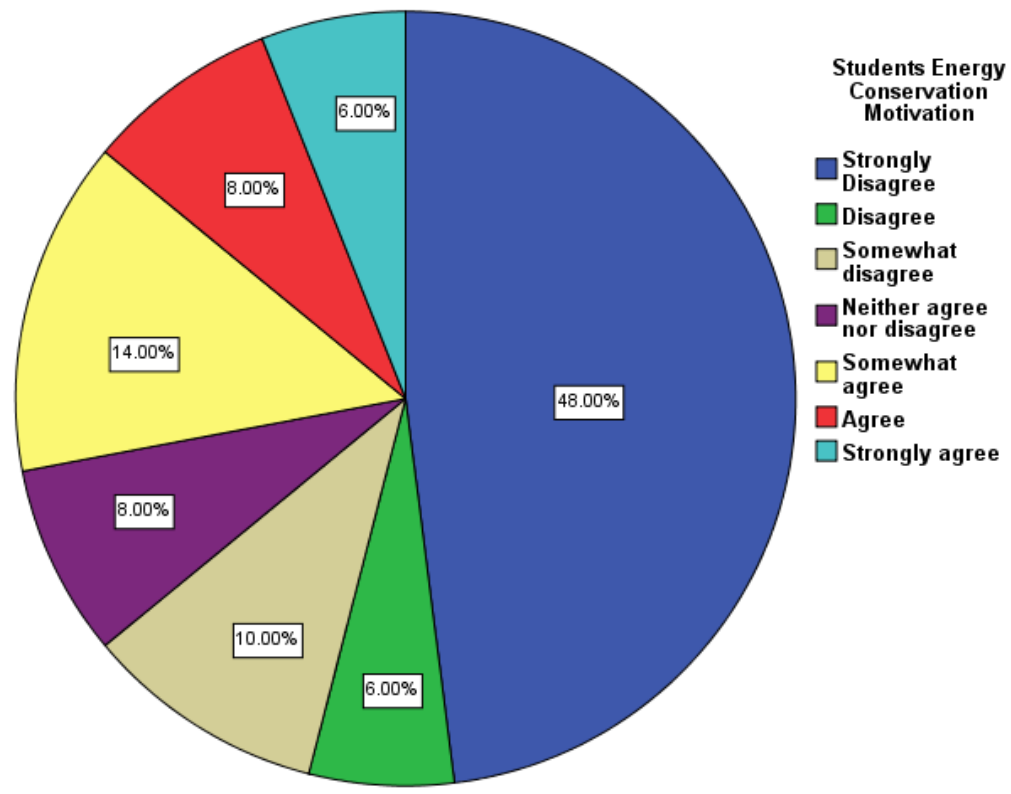

Figure 2. Students' energy conservation ability.

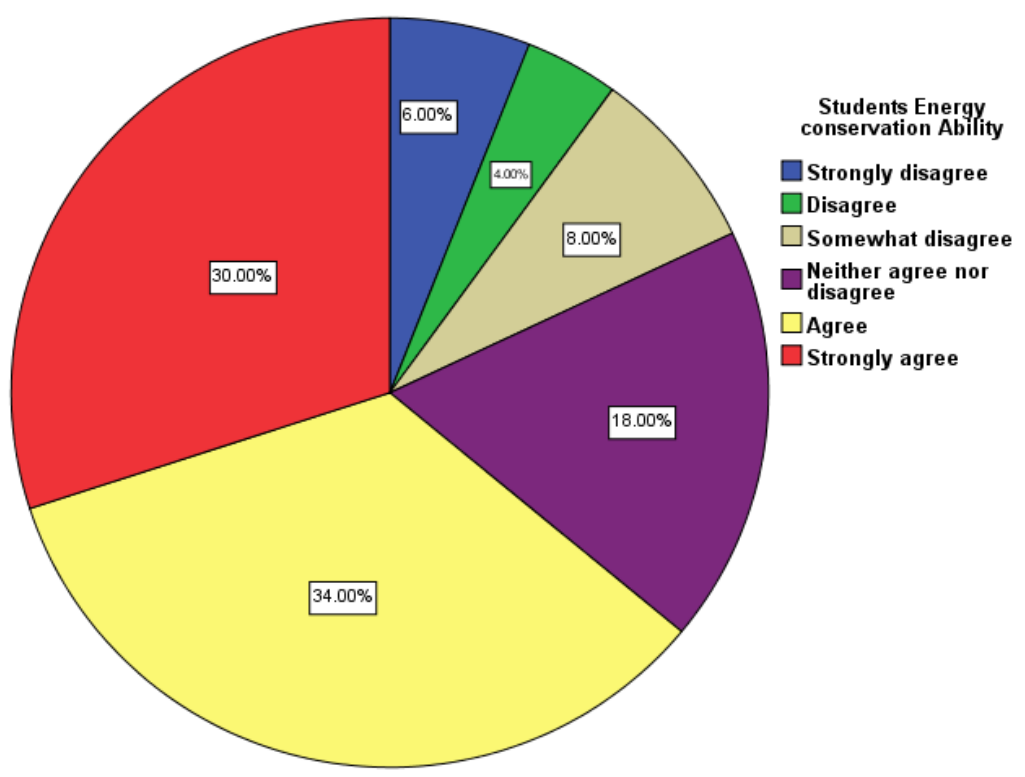


Figure 3. Required behavioral change analysis model.

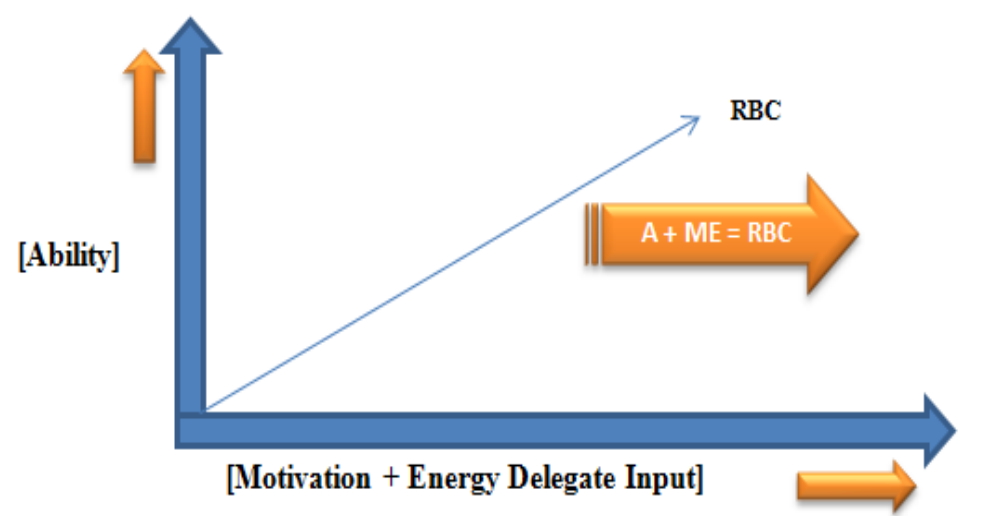

The earlier work done in energy measurement feedback systems, deployed on campus residential halls, did not address detailed students' energy conservation behavior, since the inherent social influence affecting such behavior was not tested via the surveys. Therefore, research techniques like using combinations of information feedback, smart sensing and an appointed energy delegate in each hall remain open methodologies still to be deployed. The proposed techniques are expected to motivate the students to change their behavior, which will support our assumed model of behavior. In the previous related work, there has been little analysis on energy usage after the experimental period or energy competitions are over, or on how positive students' behavior changes could be sustained continuously. This is the reason why we want to extrapolate the previous work with our proposed system in combination with an appointed energy delegate to induce motivation and sustainability. This paper will outline the proposed system architecture based on the initial survey results and previously related work. Also, techniques for measuring consumption, presenting the instant feedback on consumption and conserving electricity, using combinations of electricity smart sensors, a dedicated web interface and an appointed energy delegate will be discussed. The rest of this paper will be as follows; Section 2 will present related work, Section 3 introduces the proposed system architecture, Section 4 desribes the methodology, Section 5 presents the initial results, Section 6 discusses the challenges affecting student behavior change and section 7 presents the conclusions.

\section{Related Work}

The summary of past studies using smart sensor systems and information feedback for promoting energy savings obtained from our systematic review studies on feedback applications with particular focus on students' halls of residence, are tabulated in Table 1. The results of these studies indicate the practicality of inducing behavioral changes in building users and the possible extent by which users can adhere to energy saving interventions [1].

Table 1. Earlier research on energy saving using information feedback.

\begin{tabular}{lllll}
\hline \multicolumn{1}{c}{ Author/Yr } & Pilot/Target Group & \multicolumn{1}{c}{ Methodology } & \multicolumn{1}{c}{ Outcome } & Problem Analysis \\
\hline \multirow{2}{*}{$\begin{array}{llll}\text { Marcell K. et al. } \\
2004\end{array}$} & $\begin{array}{l}\text { Cooling the campus } \\
\text { experiences from a }\end{array}$ & $\begin{array}{l}\text { Social marketing } \\
\text { campaign; no }\end{array}$ & $\begin{array}{l}\text { Residents of the controlled } \\
\text { dormitory were exposed to an }\end{array}$ & $\begin{array}{l}\text { Lack of } \\
\text { information, } \\
\text { SSA [11] }\end{array}$ \\
pilot study to reduce & $\begin{array}{l}\text { real-time } \\
\text { feedback data. }\end{array}$ & educational program & sustainability and \\
\hline
\end{tabular}


Table 1. Cont.

electricity use at

Tufts University,

USA, using social

marketing methods.

Target Group:

Students

Petersen J.E.

et al. 2007

USA [7]

Brewer R.S.

et al. 2011

USA [8]
Dormitory residents reduce electricity consumption when exposed to real-time visual feedback and incentives.

Target Group:

Students

A Dorm Energy
Competition Focused
on Sustainable
Behaviour Change
and Energy Literacy
Target Group:
Students

Students
Using an automated monitoring system to provide real-time web-based feedback on energy and water, using education and conservation incentives.

Readings provided manually to low resolution dormitories and real-time for high resolution dormitories.

They used a

personalized homepage where students can complete tasks designed to increase energy literacy that can be verified by competition administrators. The technology and approach was evaluated in a dorm energy competition to take place in the spring of 2011, with hundreds of university freshmen. The data is provided in near real-time
Dormitory residents were

exposed to an educational

program only, while residents

of the experimental dorm were exposed to the same educational program as well as a social marketing campaign, which has a greater impact in changing the students' behavior

Dormitories that received high resolution feedback were more effective at conservation, reducing their electricity consumption by 55 per cent compared to 31 per cent for low resolution dormitories

No clear outcome as it was proposed that energy use of each pair of dormitory floors would be metered in near-real-time, and the energy literacy of students would be assessed before and after the competition. high cost of

implementation.

Hawthorns effect

Manually reading issues

Non sustainability and continuity.

Competition motivated Sustainability and continuity issues 
Table 1. Cont.

\begin{tabular}{|c|c|c|c|c|}
\hline $\begin{array}{l}\text { Odom W. } \\
\text { et al. } 2008\end{array}$ & $\begin{array}{l}\text { Social Incentive and } \\
\text { Eco-Visualisation }\end{array}$ & $\begin{array}{l}\text { Students in } 10 \\
\text { dormitories }\end{array}$ & $\begin{array}{l}\text { The competition resulted in an } \\
\text { estimated combined avoidance }\end{array}$ & $\begin{array}{l}\text { Cash prize } \\
\text { motivated. }\end{array}$ \\
\hline Australia [9] & $\begin{array}{l}\text { Displays: Toward } \\
\text { Persuading Greater } \\
\text { Change in Dormitory } \\
\text { Communities } \\
\text { Target Group: } \\
\text { Students }\end{array}$ & $\begin{array}{l}\text { received feedback } \\
\text { primarily through the } \\
\text { Energy Challenge } \\
\text { website (which } \\
\text { visualized data from } \\
\text { a utilities information } \\
\text { database), } \\
\text { Additionally, updates } \\
\text { were sent to students } \\
\text { via a Facebook group } \\
\text { and email. }\end{array}$ & $\begin{array}{l}\text { of } 33,008 \text { kilowatt hours } \\
\text { (KWh) of electricity and } \\
724,322 \text { gallons of water } \\
\text { compared to baseline } \\
\text { consumption of the previous } \\
\text { three years. }\end{array}$ & $\begin{array}{l}\text { Students subject to } \\
\text { experimental } \\
\text { condition. } \\
\text { Facebook update } \\
\text { may distract } \\
\text { attention. }\end{array}$ \\
\hline $\begin{array}{l}\text { Bekker M.J. et al. } \\
2010 \\
\text { New Zealand [10] }\end{array}$ & $\begin{array}{l}\text { Encouraging } \\
\text { Electricity Savings in } \\
\text { a University } \\
\text { Residential Hall } \\
\text { Through a } \\
\text { Combination of } \\
\text { Feedback, Visual } \\
\text { Prompts, and } \\
\text { Incentives } \\
\text { Target Group: } \\
\text { Students }\end{array}$ & $\begin{array}{l}\text { This experiment } \\
\text { investigated the } \\
\text { combined use of } \\
\text { visual prompts, daily } \\
\text { feedback, and } \\
\text { rewards to reduce } \\
\text { electricity } \\
\text { consumption in a } \\
\text { university residential } \\
\text { hall. After a 17-day } \\
\text { baseline period, } \\
\text { The experimental } \\
\text { intervention was } \\
\text { introduced in the } \\
\text { intervention hall, and } \\
\text { no change was made } \\
\text { in the control halls }\end{array}$ & $\begin{array}{l}\text { Energy usage decreased in the } \\
\text { intervention hall, but energy } \\
\text { usage did not change } \\
\text { appreciably in the control hall. } \\
\text { The resulting daytime and } \\
\text { nighttime energy usage } \\
\text { decreased in the intervention } \\
\text { hall, but energy usage did not } \\
\text { change appreciably in the } \\
\text { control hall. The resulting, } \\
\text { daytime and nighttime } \\
\text { savings were } 16.2 \% \text { and } 10 \% \text {, } \\
\text { respectively compared to } \\
\text { savings of } 3.8 \% \text { ( day) and } \\
6.5 \% \text { (night) in the control } \\
\text { hall. }\end{array}$ & $\begin{array}{l}\text { Incentive motivated } \\
\text { Manual meter } \\
\text { readings an issue } \\
\text { with accuracy. } \\
\text { Lack of continuity } \\
\text { and sustainability. }\end{array}$ \\
\hline $\begin{array}{l}\text { Marans R.W. } \\
\text { et al. } 2009 \\
\text { USA [12] }\end{array}$ & $\begin{array}{l}\text { The human } \\
\text { dimension of energy } \\
\text { conservation and } \\
\text { sustainability A case } \\
\text { study of the } \\
\text { University of } \\
\text { Michigan's energy } \\
\text { conservation } \\
\text { program } \\
\text { Target Group: Staff } \\
\text { and Students }\end{array}$ & $\begin{array}{l}\text { A multi-method } \\
\text { approach is used in } \\
\text { five diverse pilot } \\
\text { buildings including } \\
\text { focus groups, } \\
\text { behavioral } \\
\text { observations, } \\
\text { environmental } \\
\text { measures, and web } \\
\text { surveys. The } \\
\text { analyses consider } \\
\text { differences between } \\
\text { buildings and } \\
\text { between the three } \\
\text { population groups. }\end{array}$ & $\begin{array}{l}\text { Among the findings, } \\
\text { University of Michigan (UM) } \\
\text { staff is most concerned about } \\
\text { conserving energy in UM } \\
\text { buildings while students are } \\
\text { the least concerned. A } \\
\text { significant proportion of } \\
\text { survey respondents are not } \\
\text { aware of past university } \\
\text { efforts to conserve energy; } \\
\text { among those who are aware, } \\
\text { many feel that university } \\
\text { efforts are inadequate. }\end{array}$ & $\begin{array}{l}\text { Non real-time } \\
\text { feedback. } \\
\text { Multiple focuses. }\end{array}$ \\
\hline
\end{tabular}




\subsection{Analyzing the Common Lessons Learnt from the above Past Studies}

The previous papers reviewed here focused mainly on the application of smart sensors to obtain a real-time feedback or web-based information, on electricity consumption in campus or dormitories/residential halls. Most of these come from the USA, Australia, New Zealand and some ideas were also drawn from some other non-direct technical related works, like the work of Sarah Darby 2006 (The effectiveness of feedback on energy consumption) from the UK [13,14]. The previous work done indicates that there are no established studies of the use of smart sensors and real-time feedback to motivate behavior change in the UK students' residential settings. However, as categorized in Table 1, we reviewed some previous work, specifically on the applications of smart sensors to obtain a real-time electricity feedback from campus residents. We reviewed the work of Marcell K. et al. 2004, in which they used an online social marketing method to motivate Tufts University students to change their behavior towards electricity usage.

The methodology that was used here was a social marketing campaign. Based on this, they ran pilot experiments among the students living in the halls [11]. A comprehensive pilot study was undertaken over the course of eight weeks during the spring semester; two programs were undertaken in two upper-class dorms at the Medford campus. The first dorm received an educational program alone (hereafter referred to as the "educational treatment") and the second dorm received an educational program that incorporated social marketing methods (hereafter referred to as the "social marketing treatment"). These programs were designed to reach upper-class undergraduate students between the ages of 19 and 22. Upper-class students living in suite-style apartments were chosen as subjects because they tended to own large numbers of personal appliances, therefore, their behavior choices significantly impacted on electricity use in their dorm. Residents of the control dormitory were exposed to an educational program on climate change detailing how their electricity and computer use generates greenhouse gas emissions. Residents of the experimental dorm were exposed to the same educational program as well as a social marketing campaign encouraging students to turn personal computers off when not in use. Before and after surveys suggested that the social marketing campaign had a greater impact on student environmental knowledge, attitudes, and behavior than the educational program alone. Although these interventions recorded some successes, there were some problems, which needed to be addressed, such as lack of information to students from a direct real-time feedback on their electricity usage and carbon emission and high cost of implementation, which would affect the continuity, sustainability and repetitiveness of such an initiative.

All through, information was provided to the students via an online interface, on electricity conservation and carbon emission strategies, using social marketing as an enabling tool. Information strategies included breaking down complex information, personalization of the issue, fostering trust, using humor, encouraging dialogue, and distinguishing facts and their sources of opinions [15-18]. It is arguable whether social marketing web-based information strategies alone will be enough to permanently motivate students to change their behavior towards electricity conservation.

We also reviewed the work of Petersen J.E. et al. 2007, where they carried out a pilot study in a student dormitory using smart sensor, real-time visual feedback and incentives as shown below.

In Figure 4, Petersen J.E. et al. carried out experiments by deploying a "real-time-feedback" smart sensing device, in an Oberlin College dorm energy competition in 2005 [7]. Twenty-two dormitories 
were in competition over a 2 -week period with two dorms having feedback updates every 20 seconds and the other 20 getting updates every week. A smart electric sensor was embedded into the monitoring device to report the actual usage of both electricity and water. Since most students possessed computers with internet access, web pages were used to provide feedback to students. They found a $32 \%$ reduction in electricity use across all dormitories, with the two real-time feedback dorms reducing usage the most [7].

Figure 4. Smart sensing device transferring real-time data to students [7].

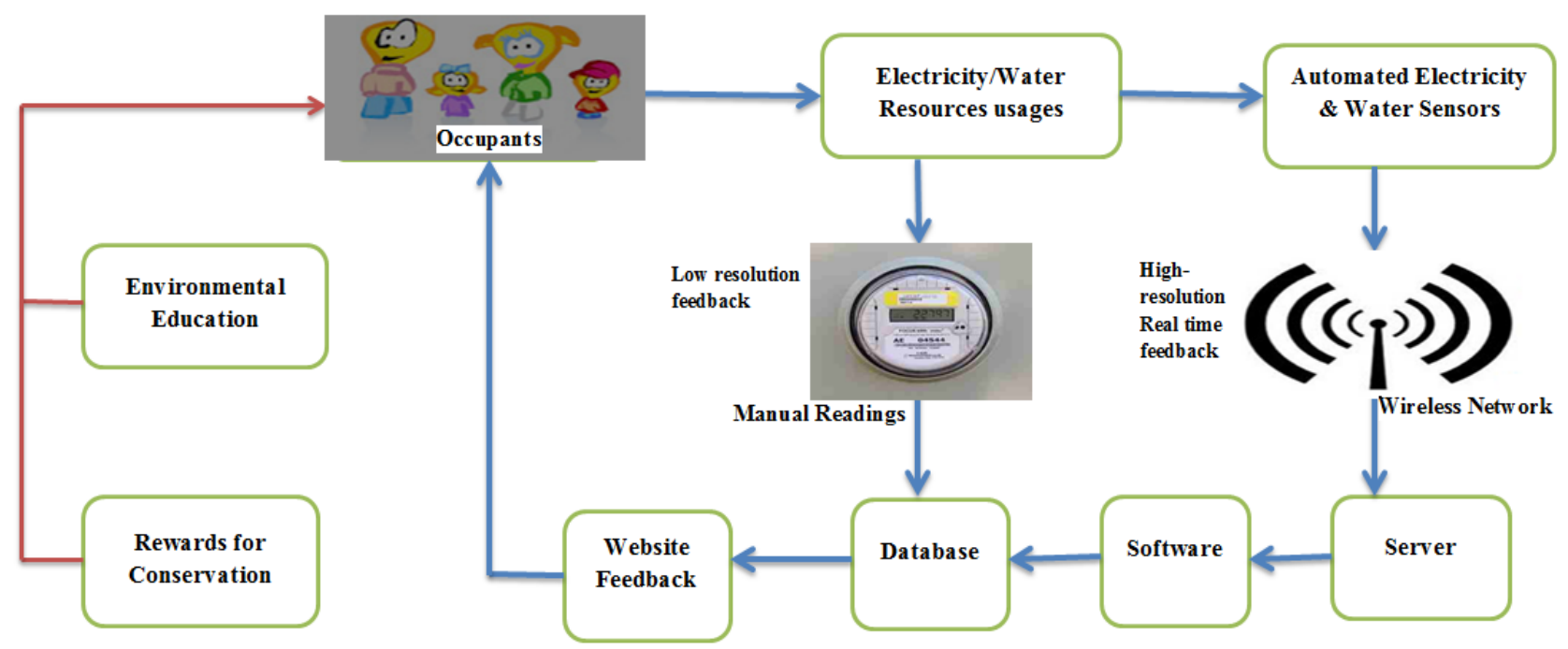

The practical implications of the results obtained in the above experiment, provide evidence that real-time resource feedback systems, when combined with education and an incentive, interest, motivate and empower college students to reduce resource use in dormitories. The degree of sustainability of such behavior change in students is still arguable, as about 20 of the dormitories were classified as "low-resolution" dormitories whereby utility meters were manually read and data were provided to students once per week during a baseline period and during a two-week "dorm energy competition" during which, feedback, education and conservation incentives were provided. Also, it is arguable that removal of incentives in such studies may affect students' motivation and indirectly affect the overall results. Therefore, this experiment might be prone to a fallback effect.

We also reviewed the work of Brewer R.S. et al. 2011, where they carried out a dorm energy competition focused on sustainable behavior change and energy literacy. Their proposed methodology is to set up a real-time feedback system as shown below, with a personalized homepage where students can complete tasks designed to increase energy literacy, which can be verified by competition administrators. The technology and approach will be evaluated in a dorm energy competition to take place in the spring of 2011, with hundreds of University freshmen [8].

The data is provided in near real-time. Their system architecture is set up in such a way that the dorm energy usage is captured by one or more meters, which are queried by WattDepot sensors and the raw data are sent to the WattDepot server. Analyses are computed and stored in cloud-based services for ease of retrieval and display in the Makahiki web application interface for visualization, the presentation of the electricity data is in near real-time. The Kukui Cup is an advanced dorm energy 
competition whose goal is to investigate the relationships among energy literacy, sustained energy conservation, and information technology support of behavior change as detailed below [8].

In Figure 5, although these studies are expected to produce interesting results in terms of energy reduction among students living in the dormitory halls, it could be argued that the students' motivations might be based on competitions only, therefore, sustainability and continuity of such behavior becomes an issue when the influence of competition is removed.

Figure 5. The Kukui Cup competition energy data display process [8].

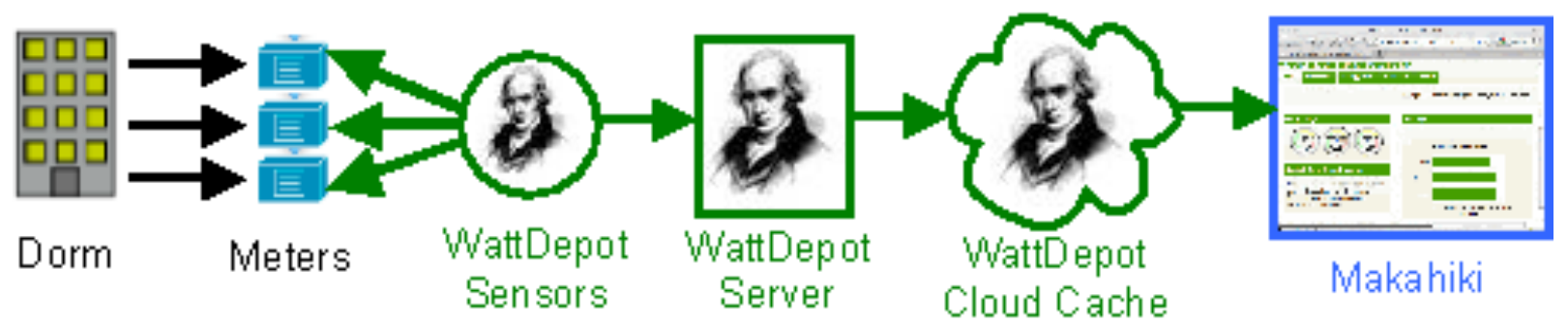

We also reviewed the work of Odom W. et al. 2008, in which they used social incentive and eco-visualization displays toward persuading a greater change in dormitory communities.

In Figure 6, the graphics describe the design, implementation, and early results of an eco-visualization of the Indiana University Bloomington campus IUB) dormitory energy and water consumption. They presented the initial results of their on-going study examining the role eco-visualizations might play in impacting dormitory communities' behavior, discussed what their findings suggested with respect to how situated displays could help improve community uptake in future work and prescribed an emerging conceptual design direction with an eye toward the intersection of situated displays and social incentive [9].

Figure 6. Real time feedback eco-visualization displays [9].

\section{Competition Standings as of April 17}

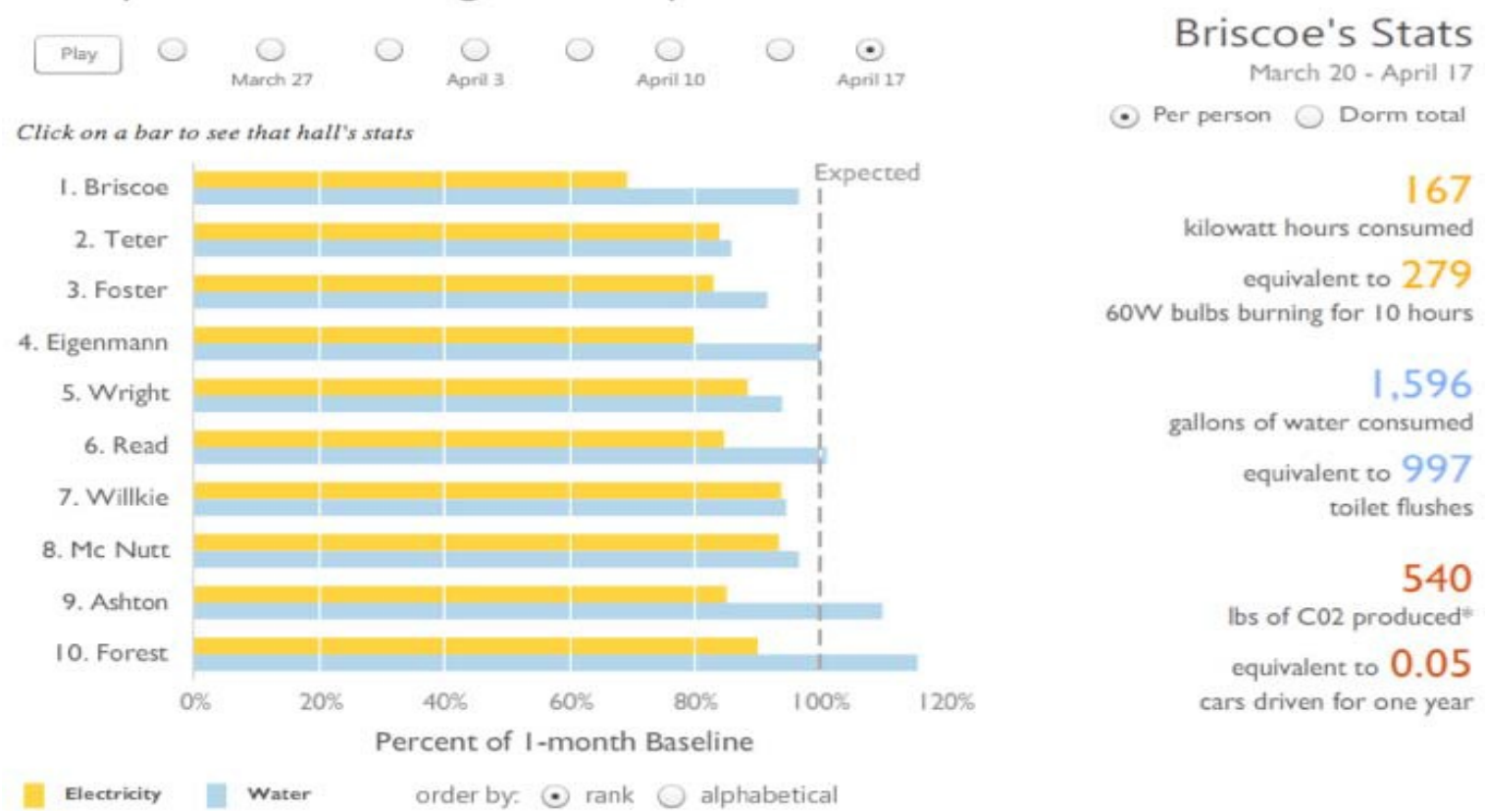


Figure 6. Cont.

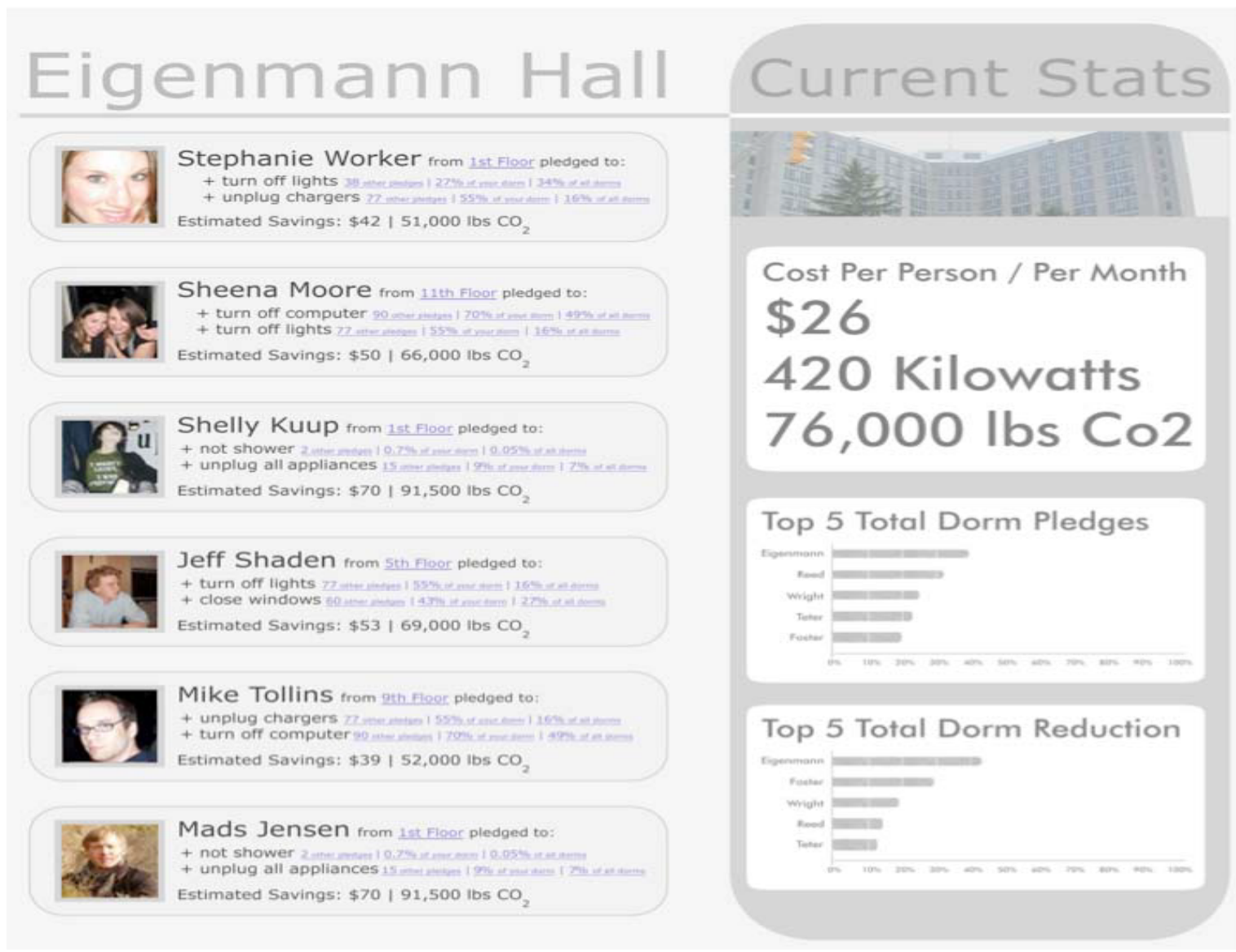

The methodology used was setting up an "Energy Challenge" which took place from March 20th to April 17th, 2008. Students in 10 dormitories on the IUB campus took part in the competition to conserve electricity and water; and the winning dorms received cash prizes and celebratory cookouts. The competition resulted in an estimated combined avoidance of 33,008 kilowatt hours (KWh) of electricity and 724,322 gallons of water compared to baseline consumption of the previous three years. Participants received feedback primarily through the "Energy Challenge" website (which visualized data from a utilities information database), however there are plans to implement this Eco-Visualization (EV) through situated displays more pervasively throughout the campus for their 2009 competition as stated in this publication by Odom W. et al. 2008.

Additionally, updates were sent to participants via a Facebook group and e-mail [9]. However, despite the results recorded by this experiment, it can be argued that the students were only motivated due to the cash prize incentive, which makes us wonder what the results would have been, if cash incentives had been removed. The students are subjected to an experimental condition, which may lead the experiment to suffer from Hawthorn's effects. Also, the use of Facebook for information sharing can be a good thing, it can, however, also be a major distraction, which could affect the experimental results.

We reviewed the work of Bekker M.J. et al. 2010 as well, who carried out experiments to investigate the combined use of visual prompts, daily feedback, and rewards to reduce electricity consumption in a university residential hall [10]. 
The methodology applied in Figure 7 involves engaging the students of two residential halls situated within $2 \mathrm{~km}$ of each other at the University of Otago in Dunedin, New Zealand. The halls were randomly assigned to either a control or an intervention condition. The control hall had 326 residents, consisting mostly of first-year University students aged 18 to 20 years (59\% female and 41\% male). The intervention hall had 190 mostly first-year residents (63\% female and 37\% male). Most rooms were of single occupancy. Heating and hot water costs were not included in the study because they were steam generated. There were no cooling systems present. After a 17-day baseline period, the experimental intervention was introduced in the intervention hall, and no changes were made in the control hall. Energy usage decreased in the intervention hall, but energy usage did not change appreciably in the control hall. In the intervention hall, mean daytime and nighttime savings were $16.2 \%$ and $10.7 \%$, respectively, compared to savings of $3.8 \%$ (day) and $6.5 \%$ (night) in the control hall [10]. Similarly, despite the results archived in this experiment, it could be argued that the fact that it is only motivated by the incentive and the electricity manual meter readings used could be a limiting factor to assess the accuracy of the results obtained. Another study reported in Table 1 is the work of Marans.R.W. et al. 2010, which they carried out at the University of Michigan campus, entitled "The human dimension of energy conservation and sustainability a case study of the University of Michigan's energy conservation program". The target group here is staff and students, and there is no application of real-time feedback systems either; for these reasons, we focused less on this study [12].

Figure 7. Plot of visual prompts and daily feedback [10].

MARTHINUS J. BEKKER et al.

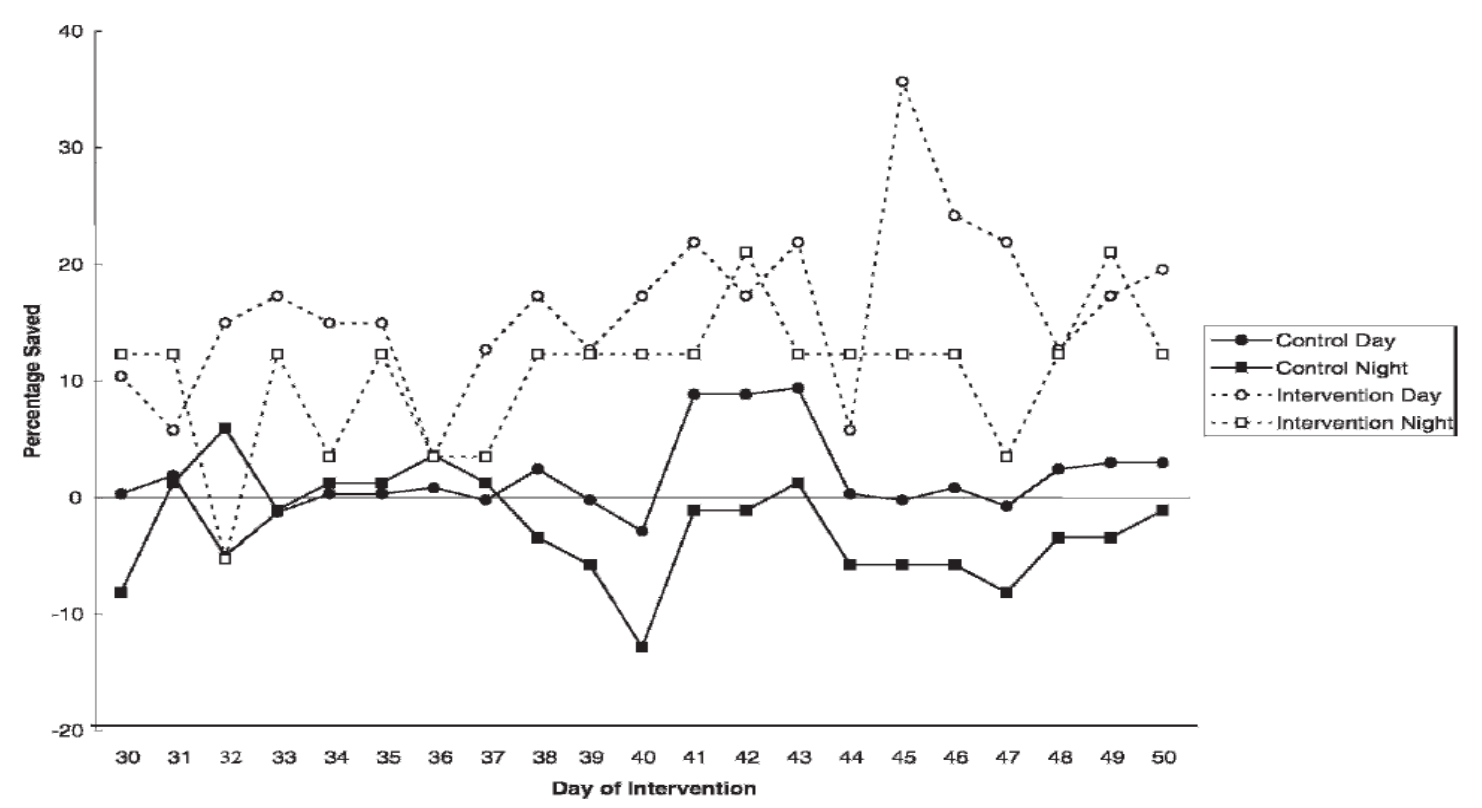

A part of this study is to propose the design of an information and communication technology (ICT) based platform, which will be used in combination with an appointed energy delegate. In the proposed system, students shall be able to visualize their real-time electricity readings in a dedicated web interface and an appointed energy delegate will induce constant motivation, which is expected to change students' behavior towards electricity consumption. Based on our area of focus and design interest using application of ICT, we reviewed the design as depicted below in Figure 8, which is 
actually a non-students' focus design. However, its technological concept will enhance the objectives of our proposed system.

Figure 8. The flow of information from the electricity meters to a user display [19].
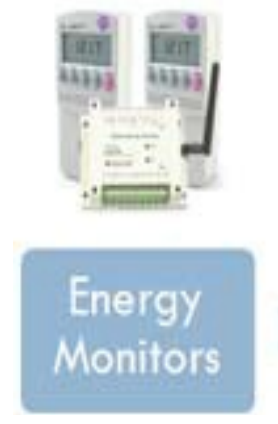
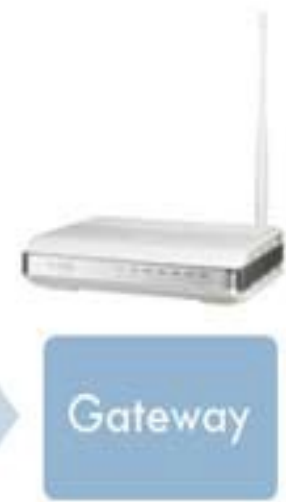
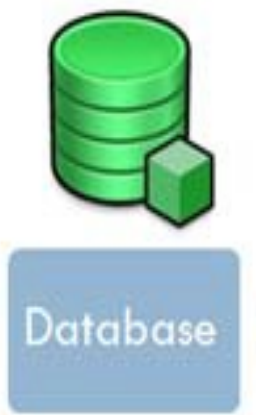
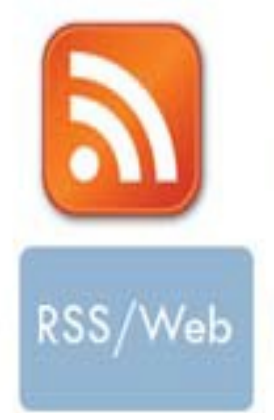
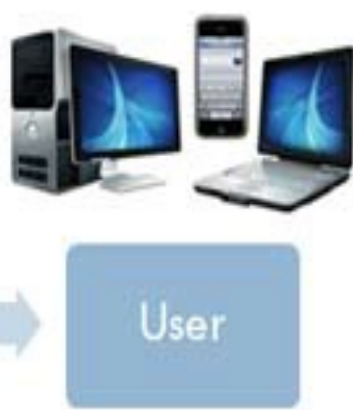

In this experimental architecture, all monitoring devices will communicate with an internet-enabled gateway to upload electricity usage information over the internet to a centralized server for processing and storage. Then the information will be made available back to users in real-time using a web interface only during the experiment period. This interface can be routed to a number of different platforms including standard web browsers as well as mobile devices. The information obtained can also be tailored to the requirements of the user [19].

Here the target group is the private households. Technologically, the concept of their real-time feedback system is very good. However, the challenge will be to extend it to permanently changing the behavior of their target group in terms of reducing its energy consumption using a psychologically tailored initiative, which is basically what our proposed design will address.

In each of the above closely related studies we reviewed they applied real-time feedback systems to some extent, and, as we noted, all their studies are based on incentive, competition, visualization, visual prompt and rewards. Also, some of the experiments are psychologically tailored initiatives in terms of constantly or permanently changing student behavior. The sustainability of these studies, literally, is affected by their various methodologies as it has been indicated after a careful review. Therefore, as the target groups are the students, these studies suffer from "fall back" and Hawthorns effects, despite the results achieved during their various experiments.

\section{Proposed System Architecture}

To help persuade the students to comply, the characteristics and tendencies of the students were studied and evolved. We christened our dedicated web interface, embedded on the proposed system architecture "Rapid Green Energy Initiative" (RGei). In the architecture shown in Figure 9, all monitoring electricity sensors are networked to communicate with an internet-enabled gateway to upload electricity usage data over the internet to a dedicated centralized server for processing, storage and access via a dedicated web interface. This system incorporates an appointed energy delegate who serves as a constant motivator to the students. However, the students can access the data in real-time, using a dedicated web interface. This interface can be routed to a number of different platforms 
including standard web browsers as well as mobile devices. The data can also be tailored to the requirements of the user or target group.

Figure 9. Smart electricity sensors showing data feedback and display process.

\section{Technological factor}

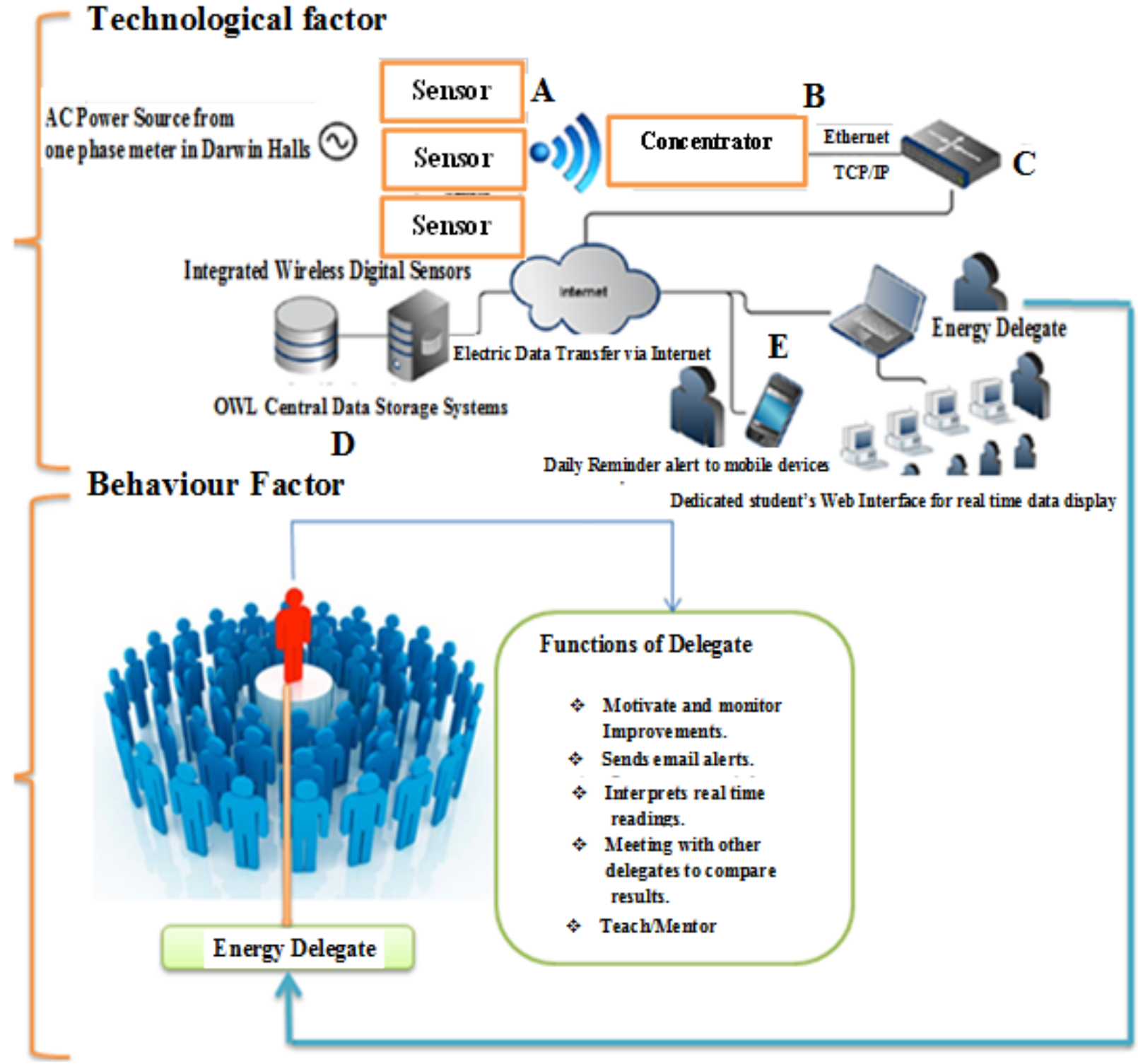

The primary aim of the embedded web interface is to provide engaging visualizations of the realtime energy consumption and carbon emissions in various students' halls of residence. Figure 9 above shows the working mechanism of the integrated digital wireless smart sensors. As listed in Figure 9, (A) shows the transfer of the energy consumption data to the central server (D) via an internet enabled gateway in real-time through the concentrator. The concentrator is the initial data processor (B), which processes the data and stores it temporarily before passing it to the Ethernet TCP/IP hub (C). The Ethernet TCP/IP hub is the "access-routing" data routing gateway, which enables the upload of electricity usage data over the internet to a centralized server for processing, storage and access via a dedicated and persuasive web interface (E). The Web interface called "Rapid Green Energy Initiative" (RGei) is a visualisable and engaging platform where the students can observe their energy consumption and carbon emission in a meaningful way. Due to the Hawthorns effects, the other 
previous interventions suffer from the lack of maintaining a constant and sustainable behavior change in students. Based on these findings, we extend the effectiveness of our system by appointing an energy delegate who will be a constant motivator to the students, by combining the efficiency of the real-time feedback. Therefore, it is expected that the real-time dedicated web interface in combination with an appointed energy delegate, will enable the students living in the halls of residence to make an informed decision to change their behavior.

These data can be programmed into multiple dedicated feedback arrays such as dedicated email alerts, mobile alerts, centralized visual displays and dedicated web interactive platform displays, links to other universally accessible social networks such as Facebook, twitter and Youtube, depending on the target audience. This persuasive interface platform will motivate behavior change among students to conserve energy and reduce carbon emission, as they can now visualize it, measure it and will have the tendency to control it.

\subsection{How the Proposed System Presents a Secured Real Time Electricity Feedback to Students}

The real-time electricity consumption is presented to students in various halls in a secure manner, as it involves logging in. The reason for secure logging in is to increase the curiosity of students who will be willing to compare their consumptions with students living in other halls. We appoint an energy delegate in each hall to act as motivator and a constant interpreter to all the students living in his hall as to how good or bad they are at conserving energy and reducing carbon emission. All the students in each hall are expected to login each day to visualize their consumption, but appointing an energy delegate is appropriate in this research because of the complexity and laxity of most students who are careless about their consumptions and carbon emissions. The detailed functions of the energy delegates are as detailed in the methodology section. Furthermore, a dedicated web interface called "Rapid Green Energy Initiative" (REGei) was developed to integrate a personalized login portal for each hall of residence to enable them to visualize their real-time energy consumption, which is updated every nine seconds from the electricity wireless sensor. Once the students are on this web interface, they can choose the name of their hall, and by clicking on it, they can be logged into their secured real-time energy consumption and carbon emissions real-time data. The proposed measurement techniques and presentation differ from the previous studies reported in this paper as detailed above. Below are the full illustrations of the display process of our proposed interface.

The dedicated interface depicted in Figure 10 was designed to promote change in behavior regarding energy consumption among students living in the Darwin residential halls. It also promotes campus environmental awareness among students, with a strong emphasis on carbon emission as a result of electricity consumption. In the planned pilot study, the appointed energy delegate will use this platform to induce motivation in the students living in his flat by showing them the amount of electricity consumed carbon and the quantity of carbon emitted on a daily/weekly basis. He will use the real-time information to perform a useful meeting once a week, where the all flat mates will contribute ideas and strategies to reduce consumption the following week. The real-time electricity readings presented to students via the dedicated web interface will help in the successful running of the planned survey study as detailed in the methodology section. 
Figure 10. Dedicated web interface designed to engage students.

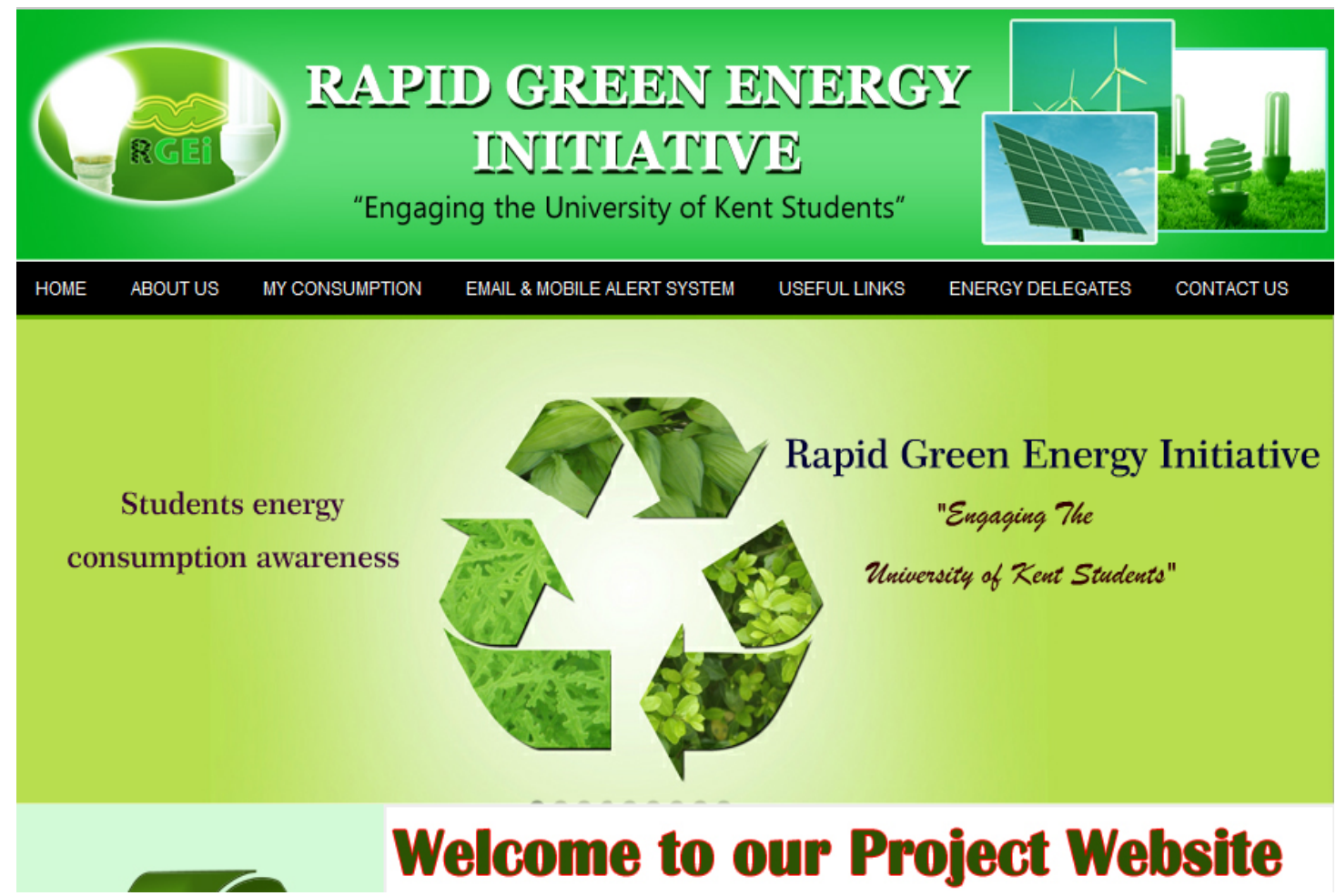

We customize a secure login so as to intensify the curiosity of various groups of students living in different halls to know how the real-time feedback has motivated others to change their behaviors. Clicking on each name of the halls as indicated in Figure 11, will take you straight to the customized login portal. We designed this based on subjective norms that exist between students [20].

Figure 11. Customized and secured login for each students' Hall.

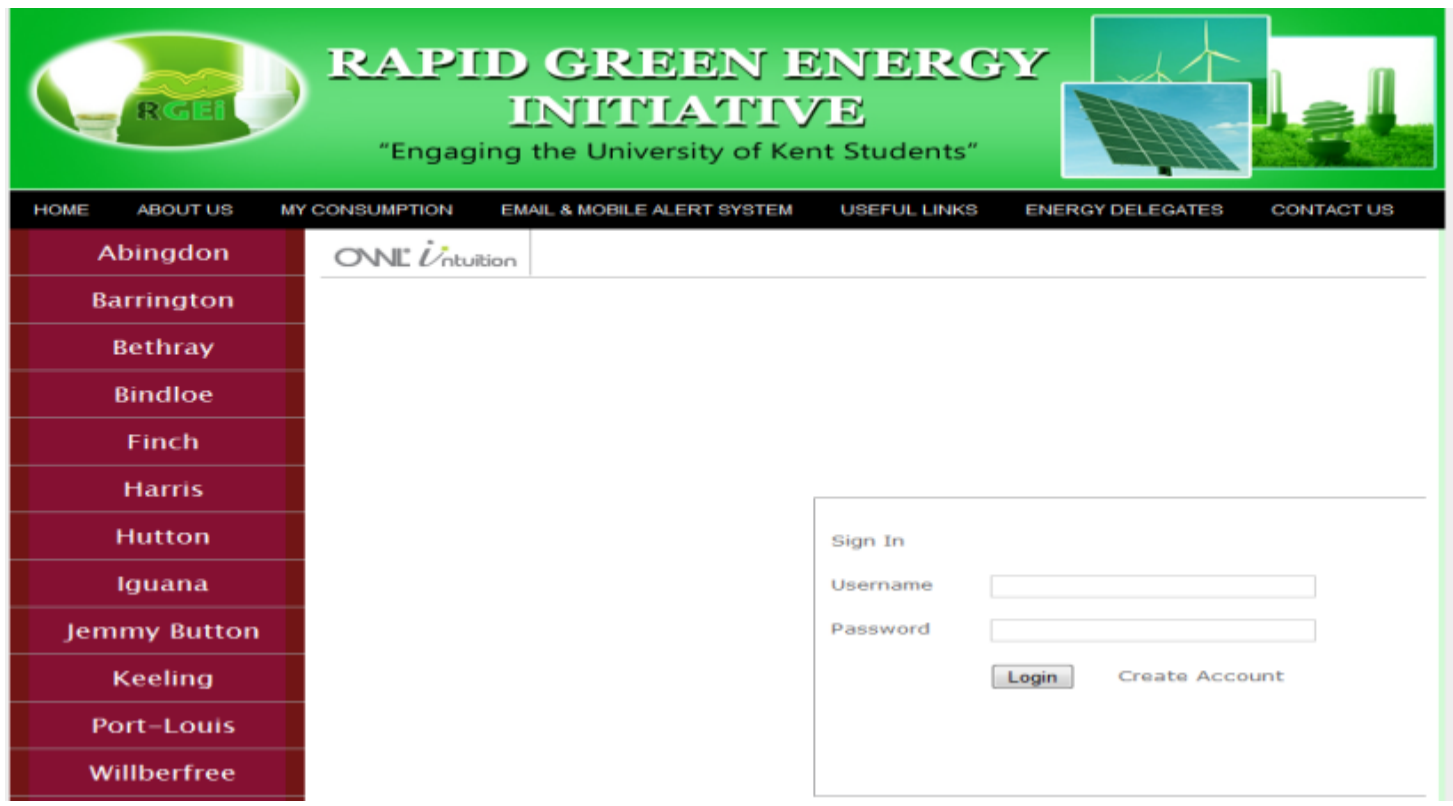

To ensure the accuracy and reliability of the electricity monitoring sensors around the students' halls of residence, we ran an initial test, which is presented in Figure 11 above. The interface is able to 
present Kwh of daily electricity consumption in real-time. The dash board in Figure 12 updates every nine seconds.

Figure 12. Engaging real-time feedback interface showing electricity data and carbon emission.

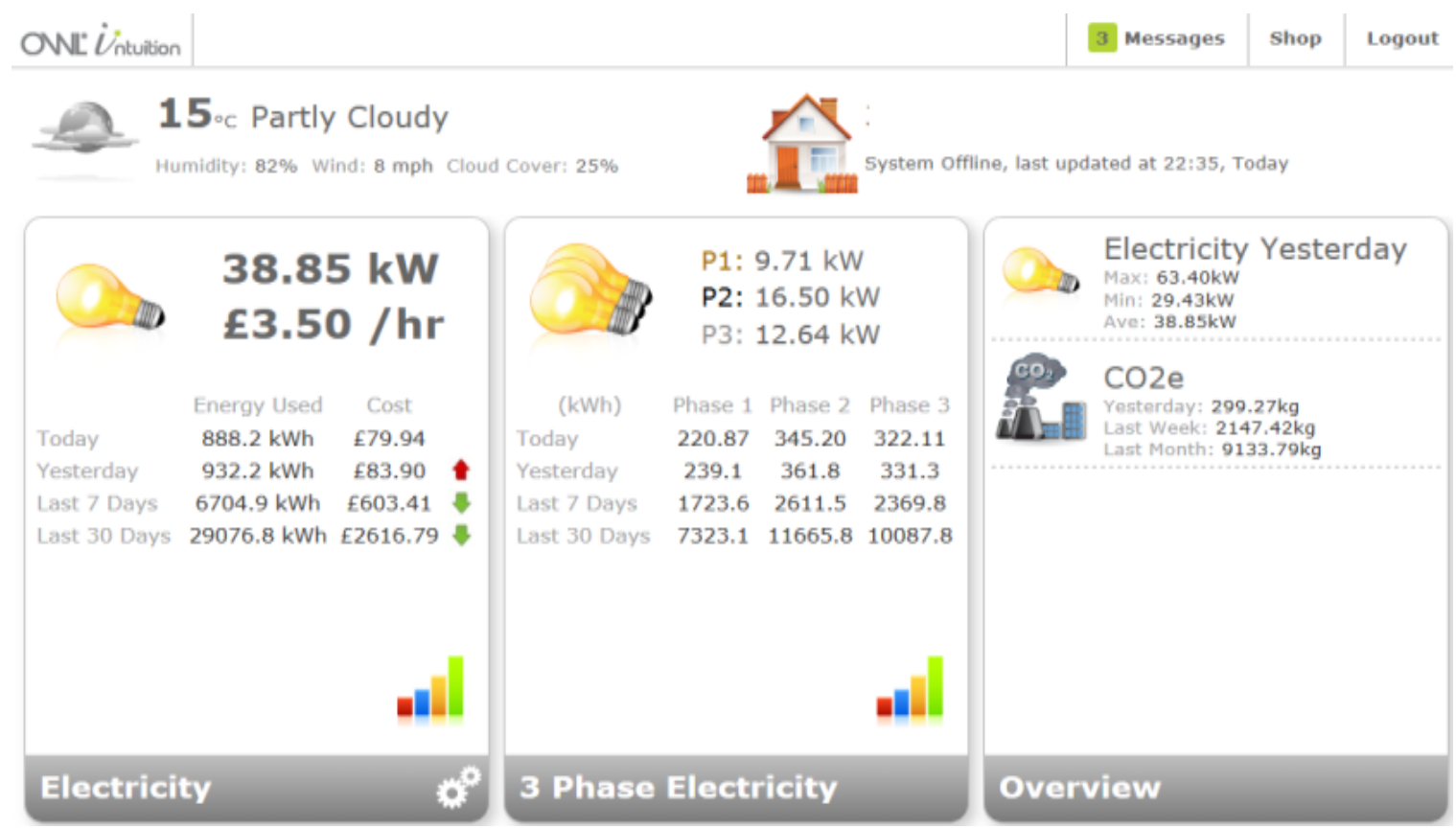

The above real-time consumption indicator, as shown in Figure 13 indicates to students how much extra electricity they have used, which is indicated by the red arrow, and also similarly how much electricity they have saved, which is indicated by the green arrow. However the above-mentioned consumption can be analyzed graphically as shown in Figure 14. The electricity used can be varied over various time frames as indicated in our dedicated interface in terms of: days, weeks, months and cost of consumption.

Figure 13. Real time indication of savings and wastages (red and green arrows).

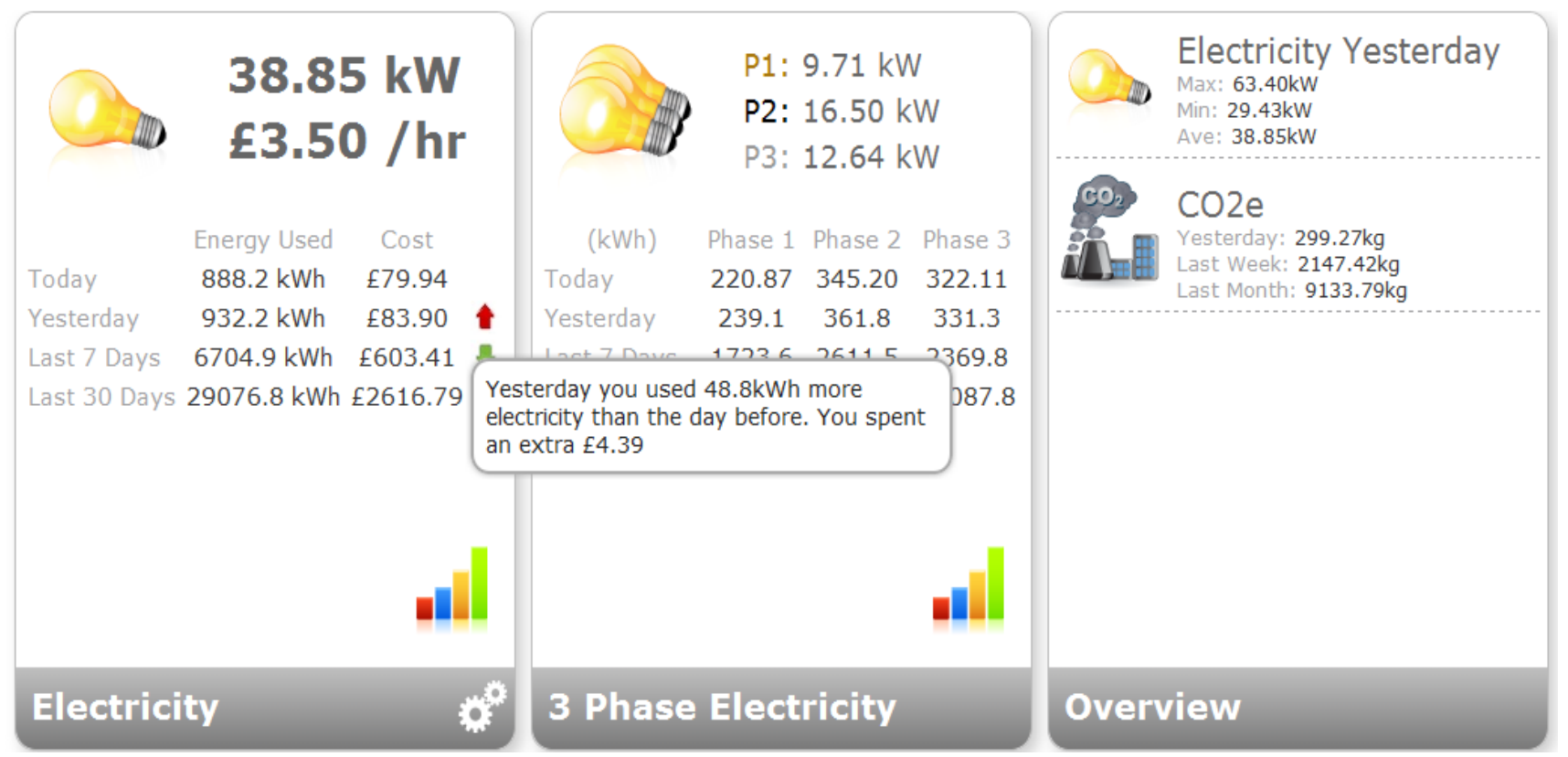


Figure 14. Graphical presentation of monthly pattern of daily consumption.

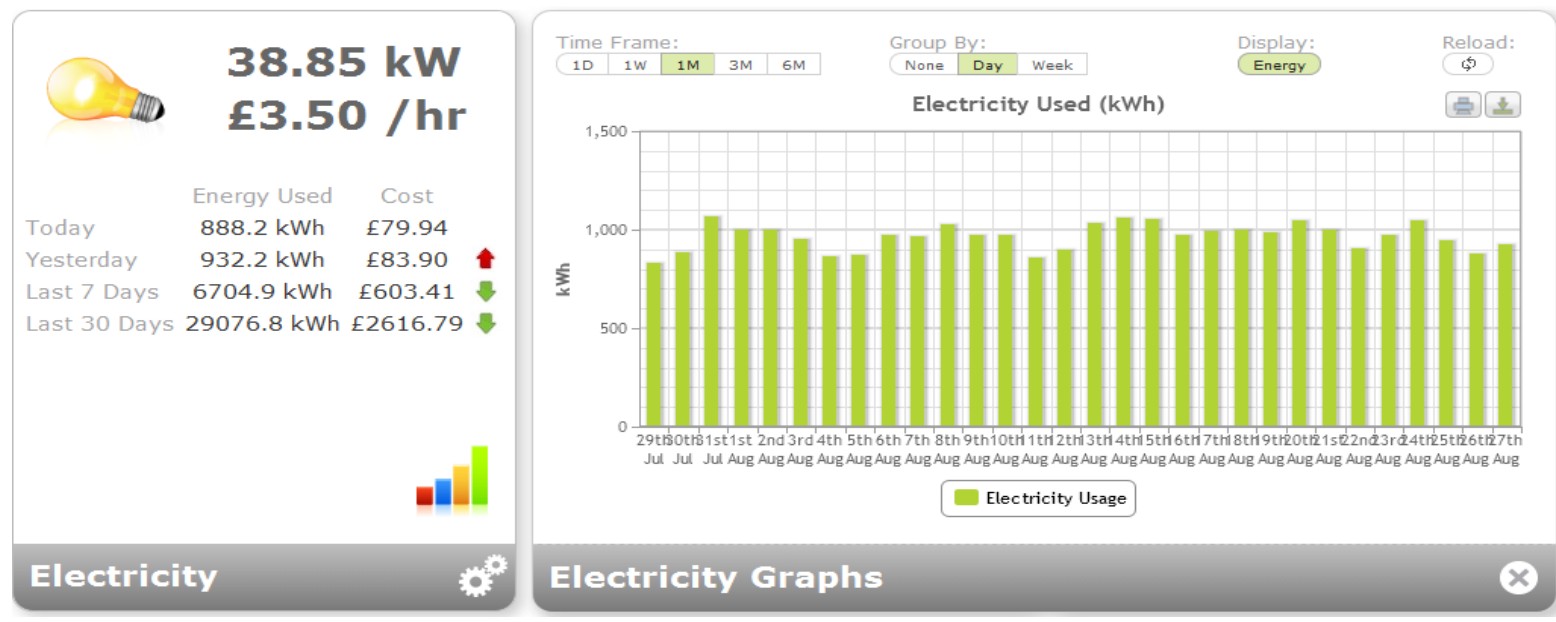

The pattern of consumption and carbon emission can also be presented to the students monthly, weekly and daily as shown in Figure 15 and Figure 16.

Figure 15. Graphical presentation of weekly pattern of daily consumption.

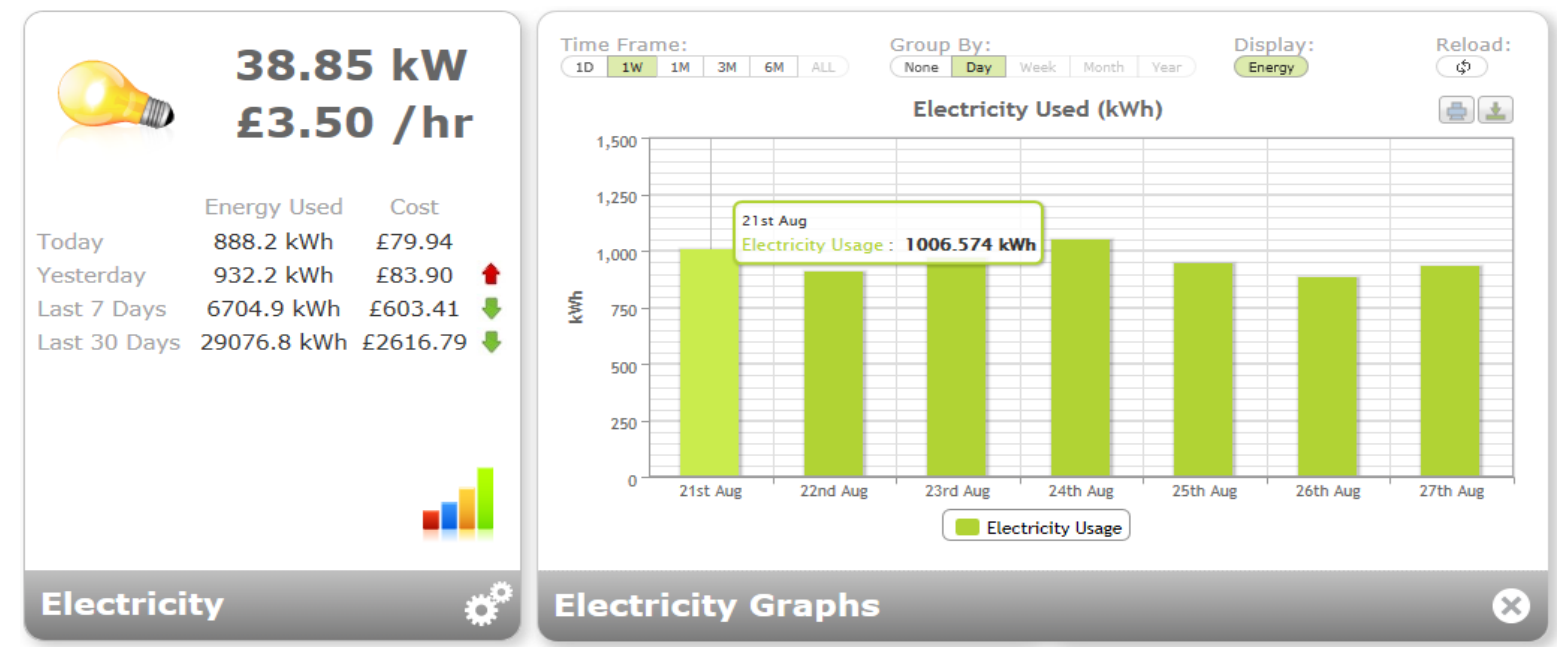

Figure 16. Graphical plot of daily pattern of hourly consumption.

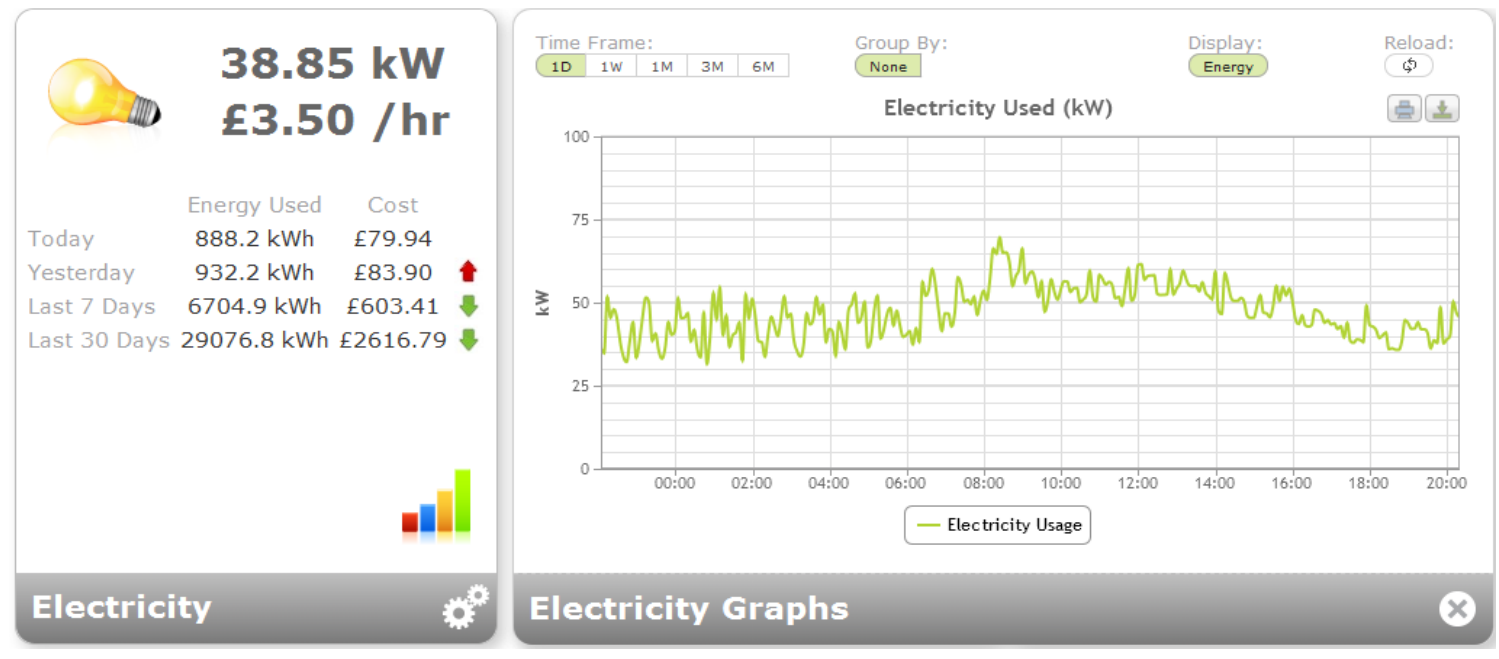




\subsection{Comparing the Proposed System with Previous Systems and Past Studies}

Comparing the previous work as described above to our proposed system architecture, the following conclusions can be derived from our proposed system. Our proposed system is designed with the initiative to improve the previous systems, such as continuous real-time feedback, student-centered design, test of social influence, sustainability of behavior change beyond experiments (establishing a platform which could be constantly repeated) by appointing an energy delegate every new academic year. It can be noted that our proposed system design is more student-centered in the sense that every student can be drawn to the interface via email reminder alert directed to their personal portal. It will be a sustainable system, which will not depend only on student experiments, incentive, visual prompt and rewards to function, rather an energy delegate can be appointed every year to use the combination of real-time feedback platform to induce and motivate behavior change and awareness.

However, for continuous sustainability of these novel ideas, the university of Kent estate is actively involved and they will make sure the intervention is carried out beyond the experiment. The design architecture recommended by us will display an engaging visualization of electricity data, using color codes to differentiate high consumption and low consumption (i.e., green low, red high). The system will be used to run various pilot studies on student's energy conservation based on social psychology theories to test the social influence existing in the halls of residences and how such social influence can affect their behavioral change regarding electricity usage. Thus, real-time feedback on electricity usage in combination with an appointed energy delegate eliminates the use of incentives and rewards so as to persuade students to change their behavior.

\subsection{Effectiveness of Energy Feedback}

A famous scientist, Lord Kelvin, has reputedly said, "If you cannot measure it, you cannot improve it." In the case of electricity usage, for householders, the only feedback they receive is a monthly bill detailing the number of kilowatt-hours used over the course of the last month. On the contrary, students do not have the means to visualize their electricity usage rates, because the cost is not directly on them. Therefore, Ed Lu of Google cites an analogy; if there were no prices on anything at the grocery store and shoppers were just billed at the end of the month [21], office workers or campus residents might never see any feedback on how much electricity they are using! To reduce energy use, students must know how much energy they are using in a continuous real-time feedback manner. Feedback systems display the consumption of a resource (such as electricity) in real-time to the user. The work presented by Sarah Darby provides a detailed survey of studies on electricity feedback systems from the past three decades $[13,14]$.

The survey of 20 studies finds that, on average, the introduction of a direct and continuous (real-time) feedback system leads to reduction of energy usage ranging from 5\%-15\% or even more. Feedback systems providing historical data (such as those provided with paper based billing statements) are not as effective ( $0-10 \%$ reductions), but can be useful for assessing the impact of efficiency measures such as improved insulation or a more energy efficient appliance, since those savings accumulate over time. However, Sarah Darby found that "consumption in identical homes, 
even those designed to be low-energy dwellings, can easily differ by a factor of two or more depending on the behavior of the householders. This finding demonstrates the significant potential to curb energy usage through changes in individual's behavior [13]. This is the reason why we proposed the combination of real-time energy feedback and appointed energy delegate so as to induce behavior change on the students living in the halls of residences.

Similarly, another survey of energy feedback was conducted by Faruqui et al., looking at 12 utility pilot programs that were installed in home displays with near-real-time feedback [22]. They found that customers who actively used the display averaged a 7\% reduction in energy usage, while those pilot programs that included pre-paid electrical services reduced their energy usage by $14 \%$. The sustainability of the energy reduction is unclear based on the pilot studies since they were of limited duration. The authors believe it is unknown whether the residents of homes with displays will acclimate to the display and cease to use it to reduce their energy usage.

This is also where the effectiveness of appointing an energy delegate is lacking. Providing energy feedback is a critical foundation for any attempt to reduce energy consumption, and the feedback itself will likely curb energy usage to some extent. However, Sarah Darby points out that while feedback is critical for energy conservation behavior, feedback alone is not always enough [14]. Other factors that lead to higher rates of energy conservation include contact with an advisor when needed, training, awareness and social infrastructure also plays a vital role.

\section{Methodology}

Based on the comprehensive analysis of past interventions in this area, as listed in Table 1, and the results obtained from the survey carried out at the hall of residence at the University of Kent [1], we propose a persuasive system that will induce a behavioural change in the students. We plan to use the proposed system in a comprehensive survey that is expected to take place among multiple freshmen of Darwin hall of residence on the Canterbury campus. However, freshmen have been targeted since they are deemed more likely to participate in the energy conservation activities. According to the research carried out in the past, it has been shown that freshmen perform well in electricity conservation interventions on campus. [3]. There are 26 residence halls in Darwin building, with about eight students per block of flat at full occupancy, resulting in 208 potential students participating per building. The pilot intervention will take place over five weeks in the spring 2013 semester. The first week will constitute a separate round of the pilot survey, called baseline period, while the actual pilot intervention will run for four weeks. Structuring the competition into rounds ensures that students that did not participate initially can start participating in a later round, without undue disadvantage.

An energy delegate will be appointed in each of the residential blocks, one per block of flats, so as to induce motivation using the combination of the effectiveness of the real time feedback readings with the energy delegate. In appointing energy delegates, we deploy certain criteria such as the basis of the first fresher student to occupy each hall. He will be the first to approach for volunteering. But if he is not interested or has no interest in energy saving, we can declare volunteering as an open option in that hall, so that anyone can volunteer to be the energy delegate of that hall.

However, to make this volunteering position attractive, we will ask the University to add this to the volunteering point scheme, which enhances each delegate's CV for future for job and leadership 
positions. The energy usage of the each student's block of flats will be measured using a smart sensory device called OWL intuition-e. Its mode of operation is described in Figure 9. This will be installed in the single-phase electrical metering systems of each block of flats. However, due to the architectural design of Darwin halls and the placement of the electrical metering of the buildings, the meters can measure the energy consumption of a whole block of flats.

The smart sensor connected to the one phase electricity meters of each block of flat will transmit electricity data every 12 seconds, enabling real-time energy feedback display in the dedicated web interface. The smart sensor data will be stored using an OWL central server, from where it can be uploaded to the dedicated web interface. Applying the real-time feedback system in combination with an appointed energy delegate, we have designed a comprehensive pilot study to help make our hypothesis very strong on students' energy behavior, real-time feedback and appointed energy delegates, using a customized web interface with a login, where the real-time electricity readings can be continuously updated every 12 seconds. Also, the effectiveness of the real-time feedback with an appointed energy delegate to encourage and enhance behavior change will be in place. Based on this, a pilot survey will be designed into two groups, with one week baseline reading for each of the eight halls to determine the actual pattern of electricity consumptions and carbon emission in each hall.

A total of 16 halls in the Darwin Residences will be monitored. Group 1 of the pilot survey consists of real-time feedback plus an appointed energy delegate (experimental group). While Group 2 of the pilot survey consists of real-time feedback with non-energy delegates (control group). The energy delegate will communicate with the students via email (daily email alert). Energy delegates will have a 20-minute group discussion at least once every week. All energy conservation strategies discussed will be documented and passed on to the researcher each week for evaluation and analysis during the one-month pilot intervention. Every two weeks, the energy delegate will distribute a 5-min simple test questionnaire on the effectiveness of the real time electricity feedback presented via their web interface and how it has motivated them to change their behavior in combination with an energy delegate. This experiment could be repeated in the next academic year, as new students will assume the positions of the last students. The results obtained could be used to make specified informed decisions on student's energy behavior in University of Kent residential halls. We will use this intervention to prove our model of behavior change as illustrated in Figure 3.

\section{Initial Results}

In the first year of this research, we carried out a survey on campus residential halls in order to get an idea about students' energy consumptions. This survey was mainly a questionnaire based and some random interviews. This initial survey was based on 50 students living in the halls of residences. We also obtained some of the campus residential electricity bills handed to us by the estate Energy Management Department. The result of the survey to some extent strongly supports our hypothesis, which mainly focuses on the lack of real-time feedback and lack of motivation to conserve electricity among students living in the halls of residence. The initial results are presented below. The statistical results were obtained using the SPSS statistical software to analyze some of our initial questionnaire data on "student's energy conservation motivations". The result clearly indicates that the students are 
not motivated to conserve electricity; this forms the basis that supports our hypothesis, which leads to the idea of our proposed system in Figure 9.

The detailed results of the data obtained investigating the energy conservation motivation by students are presented in Figure 1 with a scale of 1 to 7 representation (where 1 is strongly agree, 5 is agree and 7 is strongly disagree). Therefore the above indicates that the students have reported to have very low motivation to conserve energy, as $48 \%$ have a share in this area. Only $6 \%$ agree that they are motivated and $14 \%$ somewhat agree, the rest of the figures are not very promising or desirable. Hence it is a clear indication of the initial problem regarding student behavior change towards electricity conservation. This also gives us an idea or direction to focus on achieving successful behavior changes in students; we need to focus on "motivation" as the prime governing factor which is to a large extent the missing factor.

However, even though $6 \%$ strongly agree to be motivated, the question to be answered is whether they have the ability towards energy conservation and, hence, to understand this statistics, in reality, another detailed survey was carried out with the same student group, and the results obtained are shown in Figure 2.

On the contrary, it clearly indicates that the students have reported to have the ability to conserve energy and have the zeal in theory, as $30 \%$ strongly agree that they could do it, $34 \%$ agree, which is a total of 'positive' figure of $64 \%$ of confidence within this group for agreement.

\subsection{The Initial Electricity Usage Calculations and Carbon Emission in the University of Kent Halls of Residence}

In order to extend our initial findings in terms of students' lack of motivation to conserve electricity and reduce their carbon emission, we used the initial electricity bills and information provided to us by the University of Kent Energy Management Department. This data was used to calculate the energy consumption around Darwin halls of residence. The calculation of the results obtained is presented in Table 2. In this initial survey, there was a comprehensive coverage of all the students' energy utilities; this helped us to easily identify where the problem lay in terms of student energy utilization behavior. Also, we were able to identify the large energy guzzlers in terms of appliances. According to the real survey data, we can list below, year-wise that the total electricity used by students on appliances was identified to be a big energy guzzler in their cost and carbon emissions. This initial calculation supports our hypothesis, which focused mainly on lack of real-time electricity feedback and lack of motivation by students to conserve energy and reduce carbon emission.

Table 2. Total energy usage.

\begin{tabular}{cccccc}
\hline $\begin{array}{c}\text { Electrical } \\
\text { appliances }\end{array}$ & $\begin{array}{c}\text { Total energy in } \\
\mathbf{K W h} / \mathbf{Y r}\end{array}$ & $\begin{array}{c}\text { Average } \\
\text { used/student/KWh/yr }\end{array}$ & $\begin{array}{c}\text { Cost in } \\
\text { pounds/Yr }\end{array}$ & $\begin{array}{c}\text { Carbon emission } \\
\text { in tons/yr }\end{array}$ & $\begin{array}{c}\text { Carbon offset } \\
\text { cost/yr }\end{array}$ \\
\hline TV & 1216.18 & 24.32 & 160.29 & 0.77 & 5.39 \\
Stereo & 1459.00 & 29.18 & 192.29 & 0.92 & 6.64 \\
Refrigerators & $48,180.00$ & 963.60 & $6,350.12$ & 30.48 & 213.36 \\
Incandescent bulbs & $17,972.00$ & 359.44 & $2,368.71$ & 11.36 & 79.52 \\
CFL Bulbs & $3,507.68$ & 70.15 & 462.31 & 2.22 & 15.54 \\
Heater & $184,928.00$ & $3,698.56$ & $24,373.25$ & 116.99 & 898.23 \\
\hline
\end{tabular}


Table 2. Cont.

\begin{tabular}{cccccc}
\hline Fan & 350.40 & 7.01 & 46.13 & 0.22 & 2.33 \\
Toaster & $7,884.00$ & 156.68 & $1,039.11$ & 4.99 & 34.93 \\
Iron & 114.00 & 2.88 & 15.02 & 0.07 & 2.33 \\
Microwave & $1,095.00$ & 21.90 & 144.32 & 0.69 & 4.88 \\
Desktop & $11,826.00$ & 236.53 & $1,558.67$ & 7.48 & 52.36 \\
Laptop & $15,815.04$ & 316.30 & $2,084.22$ & 10.00 & 70.00 \\
Wash Machine & 860.00 & 17.20 & 113.35 & 0.54 & 3.78 \\
Others & $6,246.00$ & 124.92 & 823.22 & 3.95 & 27.65 \\
Totals & $\mathbf{3 0 1 , 4 5 3 . 3 0}$ & $\mathbf{6 , 0 2 8 . 6 7}$ & $\mathbf{3 9 , 7 3 1 . 0 1}$ & $\mathbf{1 9 0 . 6 8}$ & $\mathbf{1 4 1 6 . 9 4}$ \\
\hline
\end{tabular}

The above energy calculations were done based on the following parameters: number of students surveyed: 50, number of students living in the halls of residence during the above survey: 244, number of school days per year: 250, and number of days per year: 365 .

The above data obtained from the survey have enabled us to calculate and better understand energy usage in the Darwin halls of residence of the University of Kent campus. It has enabled us to identify all the energy conservation related behaviors of the students living in the above residential halls. The above tabulated energy calculation was based on 50 students surveyed and the baseline electricity data provided to us by the University estate Electricity Management Department. The above calculation indicates that heating guzzles the maximum energy in the student residential halls using $184,928.00 \mathrm{KWh}$, with an average usage of 3,698.56 KWh for heating per student in a year. This costs the campus a total amount of $£ 24,373.25$ per year. This emits 116.99 tons of $\mathrm{CO}_{2}$ into the campus environment, and it was calculated to cost $£ 898.23$ in a year to offset this $\mathrm{CO}_{2}$. This strongly indicates that we do not have any other option than to reduce energy consumption and carbon emission in the students' halls of residence.

The above analysis of energy usage increment in the students' residential hall clearly relates to the UK Government's Energy White Paper, which has one clear objective, i.e., to reduce $\mathrm{CO}_{2}$ emissions by $10 \%$ from the 1990 base by 2015 . However, in the UK, the parallel objective is to generate $10 \%$ of the UK's electricity from renewable sources by 2015 . Renewable electricity has become synonymous with reduction of $\mathrm{CO}_{2}$ emission.

However, the relationship between renewable energy sources and $\mathrm{CO}_{2}$ reduction in the power generation sector does not appear to have been examined in detail, and the likelihood, scale, and cost of emission abatement from renewable energy is very poorly understood, which leaves residents in UK with no other option but to be energy conservative [18]. Generally, $\mathrm{CO}_{2}$ emission reduction from renewable energy in the UK power system must be assessed on the basis of the impact that the accommodation of renewable power sources into the grid will have on the whole supply chain [20]. The initial survey further indicates that appliances such as lights (incidence bulbs and compact fluorescent bulbs CFL), desktops and laptop computers are the appliances put to maximum use by the students as part of their daily life.

However, change of behavior towards energy conservation should indeed reflect on the little things we do in life during electricity usage. The initial survey calculation indicates that students are using incandescent light bulbs more than the low wattage compact fluorescent bulbs (CFL). The reason for 
this according to the interview conducted around the halls of residence is that incandescent light bulbs are very cheap to buy. As a lot of students use incandescent light bulbs, which consume more electricity than the CFL fluorescent bulbs, we have proposed a system, which will be used in the campus pilot as detailed in Figure 6. We will use our new survey design to address the light bulb usages among students. See the details of the proposed methodology in Section 5. The initial random interview further reveals that the students have the ability, but are lacking motivation and information about how they can reduce their electricity consumption and carbon emissions.

The incandescent light bulbs used in the campus residential hall by the 50 students under survey reportedly used 18,000 KWh per year, which clearly indicates that a student used an average of $359 \mathrm{KWh}$ per year, and this cost the University campus $£ 2,368.71$ per year, and it emits about 11.36 tons of $\mathrm{CO}_{2}$ into the campus environments. To offset this $\mathrm{CO}_{2}$ emission, it will further cost the campus $£ 79.00$ for 11.36 tons of $\mathrm{CO}_{2}$. However, the compact fluorescent bulbs (CFL) are the best option for the students, which, from the survey results, resulted in only usage of $3 \mathrm{KWh}$ per year. This would ultimately mean that each student uses an average of $70.15 \mathrm{KWh}$ every year and costs only $£ 462.31$ to the campus and creates a $\mathrm{CO}_{2}$ emission of 2.22 tons to the environment. And it would cost only $£ 15.74$ to offset the $\mathrm{CO}_{2}$ emission of 2.22 tons.

However, analyzing the above, it can be inferred that if all the 50 students surveyed replaced their light bulbs or reading bulbs with compact fluorescent bulbs CFL, they would be able to save the University campus about $£ 1,906.40$ every year! This is quite a large savings for the campus. Generally, energy used by students is omnipresent, and the demand for energy still increases. Despite efforts in the past few years to switch to more sustainable sources of energy, fossil fuels still dominate the energy mix, resulting in harmful environmental impacts. A reduction in the use of energy is needed for Europe to meet its sustainable energy goals, apart from other policies. We can reduce our energy consumption by using energy more efficiently, investing in energy efficient appliances, appointing energy delegates to create awareness and energy conservation measures, and by adopting a more energy-efficient lifestyle; in short, by changing our behavior [14].

\subsection{Energy Wastage Identified from the Survey}

The survey calculations have enabled us to initially identify the following energy wastage behavior on campus. It was noted from the energy calculation in Table 2 that the about 50 students surveyed consumed a total of $301 \mathrm{KWh}$ per year, which costs the campus about $£ 39,731.01$ per year. Therefore, it means that on an average each student used around $6 \mathrm{KWh}$ per year. The carbon emissions released into the campus environment as a result of the above usage is 190.68 tons and will require about $£ 1,416.94$ to offset it, if we need to. It was noticed from the survey that most students were using the high wattage incandescent light bulbs instead of the low wattage compact fluorescent light bulbs (CFL) and they were also using an additional portable heater, which as left on $24 \mathrm{hrs}$ in winter. These are areas where wastage could be identified. Therefore, we will use our proposed system and techniques and methodology as indicated initially in this paper to tackle the above wastages during the full pilot intervention. However, heating is a very big problem, because even if the school management regulates it from a central hub during winter, it was indeed observed during the survey that students brought in their own private electric heaters, which were left running $24 \mathrm{hrs}$ a day in most cases. The 
survey calculations indicate that heating consumes $185 \mathrm{KWh}$ per year, costing £24,373.25. On average, each student consumes $4 \mathrm{kWh}$ per year.

The environmental impact of this is very high. 116.99 tons of $\mathrm{CO}_{2}$ are emitted into the atmosphere per year and it costs about $£ 989.23$ per year to offset it. Another significant area is the use of laptops in the student residential areas, which are left on by students for $24 \mathrm{hrs}$ in most cases. If we consider the number of students living with the 50 surveyed students, it will be a total of 244 students. Therefore, if we extrapolate our energy usage calculations to 244 students, the total energy consumed will be 1.4 Mwh per year and will cost the University about $£ 177,997.32$ per year. This will release about 854.38 tons of $\mathrm{CO}_{2}$ per year into the campus environment [23,24].

Generally, from the above total energy consumed per year, we can make a realistic assumption based on the figure of $3,880 \mathrm{kWh}$, which is the average electricity usage per household in the UK [22]. Therefore, as a comparison, according to the survey, students used 1.4 Mwh electricity per year, which would be enough to power about 47 homes in the UK per annum. Therefore, when put into perspective, it is clear to see why we need students to watch their consumption closely and use energy more efficiently. However, we will continue to use our proposed system, methodology and techniques to address the energy usage behavior in campus residential halls.

\section{Challenges Affecting Students' Behavioral Change}

In this intervention, we need to incorporate an element of psychology as it relates to students' behavioral change. The identification of the challenges that can effectively lead to behavioral changes regarding energy conservation can be done by analyzing the target group and its characteristics [25]. For example, focus groups or surveys with questionnaires can supply large amounts of data that help identify the most important influential factors, just as the surveys have indicated to us, the relationship between motivation, ability and information. However, we have noted that the factors that limit behavioral changes are as listed below. Factors that influence and affect students' behavioral changes can be typically classified into one of three types:

\subsection{Factors That Motivate the Students}

According to the initial survey and interview conducted on 50 students living in the hall of residence, motivating factors are individual, internal drivers of students' behavior. Other motivating factors are awareness, knowledge, social influence, attitude, perceived capabilities and intention. Therefore, for students to intentionally change their energy behavior, they must become aware of their energy use, pay attention to it, notice its environmental impact and be informed about the consequences of not being energy efficient. However, they must be motivated to use the available information and real-time feedback devices to control their energy use [25].

\subsection{Students' Ability and Enabling Factors}

During the survey we noted that the students' ability and enabling factors are the external constraints on behavior (social influence). However, these factors allow new behavior to be realized. These factors involve external, financial, technical, organizational and judicial resources. Examples of 
instruments that influence these factors are subsidies, availability of products in shops, and the availability of specific advice. New skills may have to be acquired to realize the desired behavior. Therefore, if the above factors are missing in the student behavior model, then there will not be any change in their behavior [25].

\subsection{Energy Behavior Based on Technological and Psychological Factors}

From the previous section, it was clear that there are some psychological challenges affecting students' behavior in terms of energy usages.

In this section we focus on the combination of technological and psychological factors affecting students' behavioral change. Real-time feedback, constant information and motivation are vital in energy related behavioral change. In this section, we turn our attention to psychological elements that are vital for behavioral change towards resource usage. In Figure 17, we present several models of energy-related behavioral change strategies. The analysis of Figure 17 indicates that no behavioral change occurs if technological factors and psychological factors are not present together. What this describes to us is that both factors have to be present for energy conservation change behavior to occur.

Figure 17. Technological and psychological factors in energy conservation behavior.

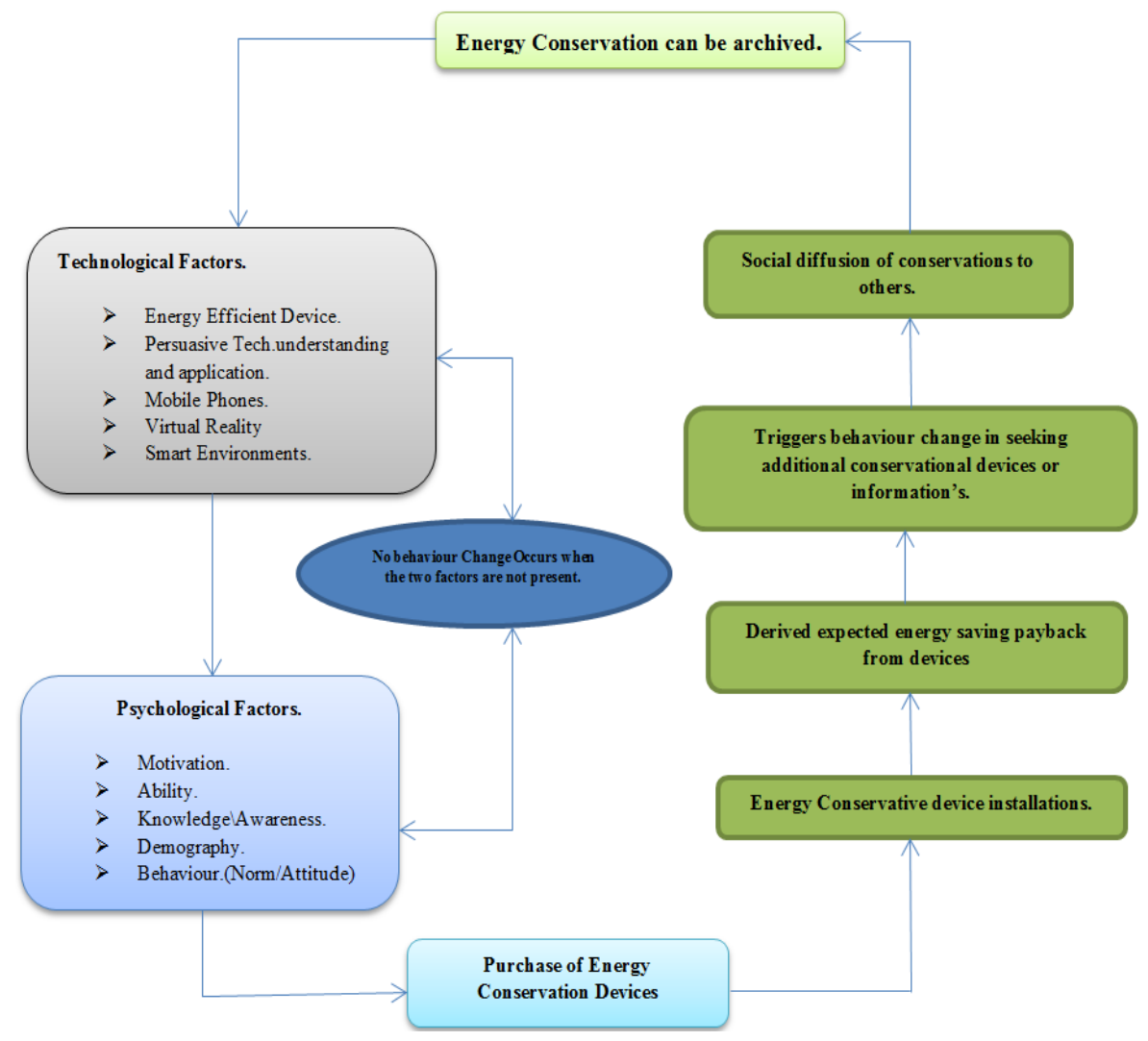

Therefore, when both are present, it triggers the need and the awareness to purchase energy conservation devices, energy conservation device installations, derives expected energy saving payback from devices, triggers behavior change in seeking additional conservational devices or information on them, social diffusion of conservation to others and how energy conservation can be 
archived. This model forms part of our ideology in designing our proposed systems in Figure 9 with the combination of an appointed energy delegate. This indicates that greater energy saving results can be achieved when technology is combined with human input to affect a change.

\subsection{Energy Behavior Analysis}

In order to further investigate the psychology of students' behavioral change, we reviewed the work of some environmental research psychologists. This forms the basis of our ideology in designing a behavioral change model, which can be used to prove the overall result of our intervention. The details of our model are explained in Figure 3. Figure 18 establishes various models to explain environmentally relevant behavior and provides a basis for successful behavioral change. Matthies (2005) has reviewed concepts and findings from the entire discipline and incorporated them into an empirical model of environmentally relevant behavior.

This model can be useful in clarifying why and how feedback on electricity consumption can reduce consumption [24]. These models can be grouped into three categories, namely norm activation, motivation and evaluation. First, the model draws attention to habits that might be environmentally destructive and need to be broken up in order to encourage behavior towards energy conservation on a long-term basis. Secondly, it points to several aspects of consciousness: One needs to be conscious of environmental problems, of the consequence of one's own behavior and of one's possibilities for changing that behavior (the latter often being labeled as a "sense of control"). In addition, norms are relevant as well as other, sometimes conflicting, motives (like convenience, or financial savings).

In an evaluation phase, people estimate various (moral, environmental, personal) costs and benefits in order to come to a conclusion on how to act, so as to be energy conservative. Thinking along these lines enables us to detect ways in which real-time feedback can contribute to our proposed system when combined with an appointed energy delegate. First, it can direct attention towards electricity consumption, demonstrating to the students how much electricity they consume daily. Therefore, in this way, habits are broken and a door is opened to reflect on one's behavior and make mindful decisions. Secondly, the model in Figure 18 raises consciousness in various ways. It can highlight environmental impact and one's own input into it. It can also give the student logical control over their behavior [26].

Figure 18. A model of environmentally relevant behavior.

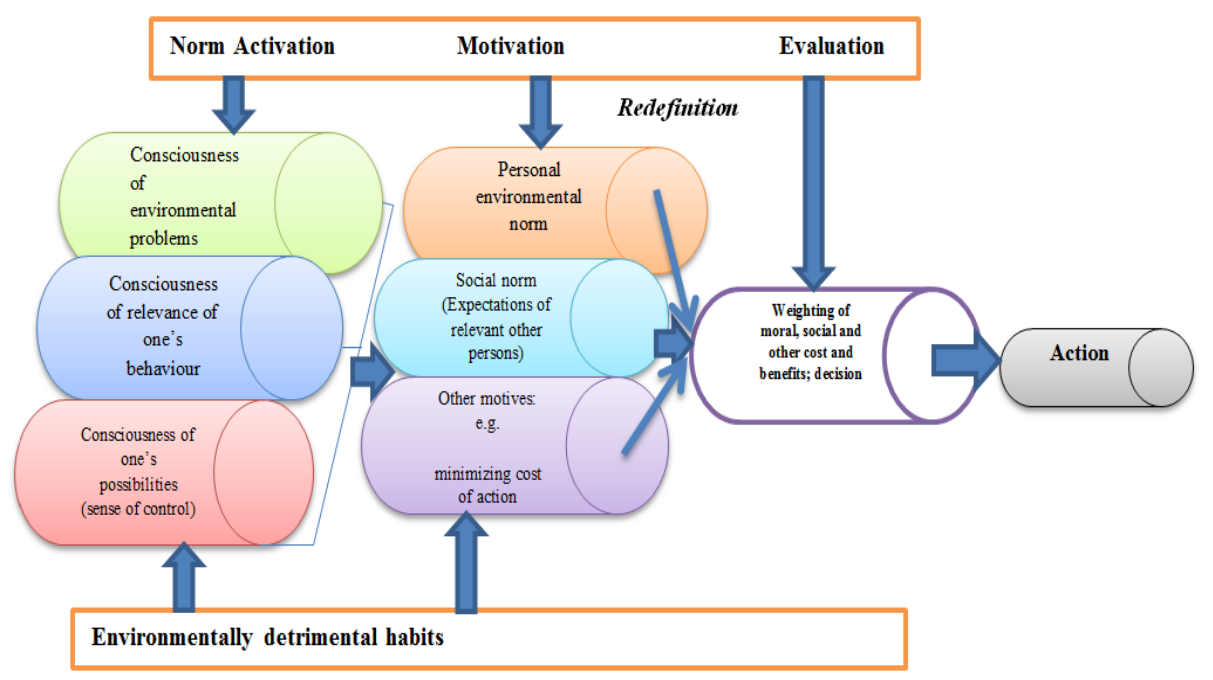




\subsection{A Model to be Proven after the Intervention}

After the full pilot intervention as detailed in Section 5, we will prove that the total results obtained with the model as explained in Figure 3, which we have designed based on an idea borrowed from B.J. Fogg [6]. In this project, we modified this theorem to suit our project and target audience. This indicates that the required behavior change will be achieved by students if they have a high ability to conserve electricity and are motivated via energy delegate persuasion, using real-time energy feedback. This will be related to overall electricity cost and carbon emissions.

Ability $+[$ Motivation + Energy Delegate Input $]=$ Required Behavioral Change.

\section{Conclusion}

In this paper we have clearly outlined our proposed contribution and methodology for archiving our contributions during the planned full pilot intervention. We have successfully carried out an initial survey and, based on the results obtained in Section 6, we have proposed a novel integrated system combining environmental and human psychology with technological feedbacks to assist real-time energy conservation and carbon reduction among students living in the halls of residence. The proposed system initiative was designed to address the complexity in students' energy consumption behavior as detected during the initial survey. The combination of real-time electricity feedback and appointed energy delegate is expected to promote awareness among students towards contributing positively to their immediate environment and to the global climate change. Also, if the full pilot project is successfully completed, it can be implemented in other universities, organizations and companies across the world where wasteful electricity consumption remains undetected. This will enable them to make a meaningful contribution in the reduction of cost, electricity consumption and carbon emission. The proposed system, apart from serving as a direct persuasive interface for each student, is designed to have a link to wider social networks, where students from other continents can share their views on energy conservation initiatives.

In the large pilot studies planned at the end of this year, we plan to fully investigate the students' energy conservation, using the dedicated web interface called "Rapid Green Energy Initiative" (RGei), developed by us, and an appointed energy delegate in each of the students' halls. It is planned to include hundreds of students living in Darwin halls of residence. This study will feature automated consumption data provisioned through smart electricity monitoring sensors, a dedicated web interface and an appointed energy delegate. The results obtained from this intervention can be used to prove our student model of behavior as detailed in Figure 3, (Ability + [Motivation + Energy Delegate Input $]=$ Required Behavioral Change).

\section{References}

1. Fischer, C. Feedback on household electricity consumption: A tool for saving energy? Energy Effic. 2008, 1, 79-104.

2. EDF Energy Homepage. Available online: http://www.edfenergy.com (accessed on 16 October 2011). 
3. Peschiera, G.; Taylor, J.E.; Siegel, J.A. Response-relapse patterns of building occupant electricity consumption following exposure to personal, contextualized and occupant peer network utilization data. Energy Build. 2010, 42, 1329-1336.

4. International Energy Agency, 2005. World Energy Outlook 6th ed; Paris, France, 2005. Avialable online: http://www.worldenergyoutlook.org/media/weowebsite/2008-1994/WEO2005.pdf (accessed on 16 June 2012).

5. Scottish Power Raises Gas and Electricity Prices. Available online: http://www.guardian.co.uk/ money/2012/oct/15/scottish-power-raises-gas-electricity-prices (accessed on 16 October 2011).

6. Fogg, B.J. Persuasive Technology: Using Computers to Change What We Think and Do; Morgan Kaufmann: San Francisco, CA, USA, 2003; pp. 31-65.

7. Petersen, J.E.; Shunturov, V.; Janda, K.; Platt, G.; Weinberger, K. Dormitory residents reduce electricity consumption when exposed to real-time visual feedback and incentives. Int. J. Sustain. High. Educ. 2007, 8, 16-33.

8. Brewer, R.S.; Lee, G.E.; Johnson, P.M. The Kukui Cup: A dorm energy competition focused on sustainable behaviour change and energy literacy. In Proceedings of the 44th Hawaii International Conference on System Sciences, Koloa, Kauai, HI, USA, January 2011.

9. Odom, W.; Pierce, J.; Roedl, D. Social incentive \& eco-visualization displays: Toward persuading greater change in dormitory communities. Int. J. Sustain. High. Educ. 2008, 1, 16-33.

10. Bekker, M.J.; Cumming, T.; Osborne, N.K.P.; Bruining, A.M.; Mclean, J.I.; Leland, L.S. Encouraging electricity savings in a university. J. Appl. Behav. Anal. 2010, 1, 327-331.

11. Marcell, K.; Agyeman, J.; Rappaport, A. Cooling the campus: Experiences from a pilot study to reduce electricity use at Tufts University, USA, using social marketing methods. Int. J. Sustain. High. Educ. 2004, 5, 169-189.

12. Marans, R.; Edelstein, J. The human dimension of energy conservation and sustainability: A case study of the University of Michigan's energy conservation program. Int. J. Sustain. High. Educ. 2010, 11, 6-18.

13. Darby, S. The Effectiveness of Feedback on Energy Consumption; A Review for DEFRA of the Literature in Metering, Billing, and Direct Displays: Oxford, UK, April 2006.

14. Darby, S. Making it obvious: Designing feedback into energy consumption. In Proceedings of the 2nd International Conference on Energy Efficiency in Household Appliances and Lighting, Naples, Italy, January 2001; pp. 685-696.

15. Costanzo, M.; Archer, D.; Aronson, E; Pettigrew, T. Energy conservation behaviour: The difficult path from information to action. Am. Psychol. 1986, 41, 521-528.

16. Oleckno, W. Guidelines for improving risk communication in environmental health. J. Environ. Health 1995, 58, 20-24.

17. Townsend, S.; Dev, S.; Kev, U. Green Futures, September 20, 2001; pp. 34-35.

18. Wright, M.; Hooper, S. Break it down, open it up. Green Futures, September 19, 2001; pp. 21-24.

19. Delmas, M. Behavioural Responses to Real-Time Individual Energy Usage Information; Technical Proposal for State of California Air Resources Board Research Division: Sacramento, CA, USA, October 2010.

20. Shen, D.; Laffey, J.; Lin, Y.; Huan, X. Social influence of perceived usefulness and ease-of-use of course delivery systems. J. Int. Online Learn. 2006, 5, 270-282. 
21. Google's Energy Ideas Might Emerge Under Open Source License or Not. Available online: http://green.blogs.nytimes.com/2008/10/28/googles-energy-ideas-might-emerge-under-open-sourcelicenses-or-not/ (accessed on 7 July 2012).

22. Faruqui, A.; Sergici, S.; Sharif, A. The impact of informational feedback on energy consumption -A survey of the experimental evidence. Energy 2010, 35, 1598-1608.

23. White, D. Reduction in Carbon Dioxide Emissions: Estimating the Potential Contribution from Wind-Power, 2004. The Renewable Energy Foundation Web Site. Available on line: http:// www.ref.org.uk/publications/171-reduction-in-carbon-dioxide-emissions-estimating-the-potentialcontribution-from-wind-power (accessed on 20 July 2012).

24. The Carbon Foodprint and Carbon Offset Option. Available on line: http://www.carbonfootprint.com/ offset.aspx? $=190.71 \& r=$ ShopOffset (accessed on 28 June 2012).

25. Linden, A.L.; Kanyama, A.C.; Eriksson, B. Efficient and inefficient aspects of residential energy behaviour: What are the policy instruments for change? Energy Policy 2006, 34, 1918-1927.

26. Fischer, C. Influencing Electricity Consumption via Consumer Feedback: A Review of Experience. In Proceedings of eceee 2007 Summer Study: Saving Energy-Just Do It! La Colle sur Loup, France, June 2007; pp. 1873-1884.

(C) 2012 by the authors; licensee MDPI, Basel, Switzerland. This article is an open access article distributed under the terms and conditions of the Creative Commons Attribution license (http://creativecommons.org/licenses/by/3.0/). 